\title{
Phase Analysis of Portland Cement by Combined Quantitative X-Ray Powder Diffraction and Scanning Electron Microscopy
}

\author{
Paul E. Stutzman ${ }^{1}$, Pan Feng ${ }^{2,1}$, and Jeffrey W. Bullard ${ }^{1}$ \\ ${ }^{1}$ National Institute of Standards and Technology, \\ Gaithersburg, MD 20899 \\ ${ }^{2}$ Southeast University, \\ Nanjing, Jiangsu 210096, China \\ paul.stutzman@nist.gov \\ pan.feng@nist.gov \\ jeffrey.bullard@nist.gov
}

\begin{abstract}
$\mathrm{X}$-ray powder diffraction (XRD) has been used for several decades to identify and measure the mass fractions of various crystalline phases in portland cement. More recently, a combination of scanning electron microscopy with X-ray microanalysis (SEM/XMA) and image processing has been shown to enable the quantitative characterization of microstructural features in these materials. Each technique can furnish some information that is not accessible from the other. For example, SEM/XMA can identify the microstructural location and morphology of calcium sulfate minerals, while only XRD can determine the relative abundance of the different forms of calcium sulfate, such as gypsum $\left(\mathrm{CaSO}_{4} \cdot 2 \mathrm{H}_{2} \mathrm{O}\right)$, bassanite $\left(\mathrm{CaSO} 4 \cdot \frac{1}{2} \mathrm{H}_{2} \mathrm{O}\right)$, and anhydrite $\left(\mathrm{CaSO}_{4}\right)$. This document describes how $\mathrm{XRD}$ and SEM/XMA can be used together to establish and validate the portland cement phase composition and microstructure. Particular emphasis is laid on step-by-step procedures and best practices for XRD specimen preparation, data collection, and intepretation. Similar detail has been given recently for SEM/XMA [Stutzman et al., NIST Tech Note 1877, U.S. Department of Commerce, April 2015]. The methods are demonstrated for three portland cement powders, through which apparent discrepancies between the results of the two methods are identified and procedures are described for resolving the discrepancies and quantifying uncertainty.
\end{abstract}

Key words: materials characterization; microstructure; portland cement; scanning electron microscopy; X-ray diffraction.

Accepted: March 2, 2016

Published: April 11, 2016

http://dx.doi.org/10.6028/jres.121.004

\section{Introduction}

The first application of X-ray powder diffraction (XRD) to portland cement powder was made by Brownmiller and Bogue in 1930 [1], only 35 years after X-rays were discovered. At the time, portland cement clinker was thought to be composed primarily of either a complex single compound containing lime, alumina, and silica, or separate silicate compounds containing varying amounts of lime. In their groundbreaking study, Brownmiller and Bogue compared X-ray diffraction patterns obtained from a commercial portland cement clinker to those obtained from individually synthesized phases. The comparison (Fig. 1) demonstrated the presence of tricalcium silicate (alite) as the primary clinker phase, as postulated previously by Henri Le Chatelier [2, 3] and observed by Törnebohm [4], and also indicated phases that are now called belite (dicalcium silicate), tricalcium aluminate, ferrite, and periclase. 


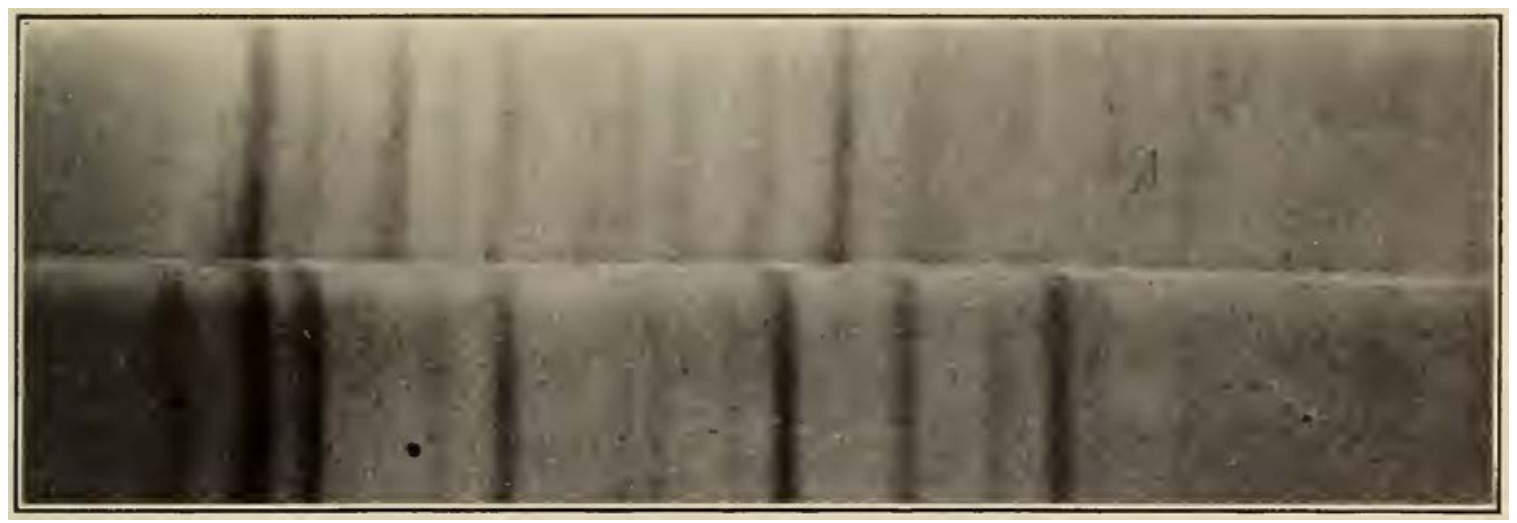

Fig 1. X-ray powder diffraction pattern first published as Fig. 1 in Ref. [1], obtained using a Debye-Scherrer camera, comparing a mixture of individually synthesized dicalcium silicate and free lime (upper) to synthesized tricalcium silicate (lower). The dissimilarity in the patterns proved that tricalcium silicate in clinker is not a mechanical mixture of dicalcium silicate and free lime.

ASTM Subcommittee C01.23 on Compositional Analysis of Hydraulic Cements established a Task Group on XRD in 1978 to develop a standard test method for using XRD to determine the proportion of phases in portland cement and portland cement clinker. Their work led to the creation of such a test method, ASTM C 1365, in 1998 [5]. During the 20 years of work leading up to that test method, quantitative XRD analysis of cement transitioned from measuring the area under a single peak for a given phase to whole-pattern fitting using Rietveld refinement [6]. Improvements in structural models for the major mineral phases has led to greater accuracy and confidence in results of the methods. Today, XRD is used routinely in the cement industry for bulk phase analysis.

Quantitative microstructure imaging of cement, using scanning electron microscopy in combination with X-ray microanalysis and image processing, is a more recent development in compositional analysis of cement, although its roots may be traced back to optical microscopy techniques first used by Le Châtelier [3] to investigate portland cement clinker composition. Quantitative optical microscopy methods began with Delesse [7], who recognized the relationship between the area fraction of a mineral in a 2D section and its 3D volume fraction in the material. Microscopic phase composition analysis evolved by subsampling the microstructure through linear traverse and point sampling to obtain quantitative estimates of mineral abundance. These methods are now more than a century old but are still used today in many disciplines.

Scanning electron microscopy combined with X-ray microanalysis (SEM/XMA) and image analysis can now produce a set of high-resolution image fields from a single material. These image sets are sufficiently consistent that feature extraction and quantitative measurement by digital image processing are possible. In this case, the mineral constituents are digitally traced and extracted from the bulk microstructure by a set of operations termed image processing and image analysis, which supplant the older operations with semi-automated pixel counting to determine phase abundance. Images can therefore be analyzed more rapidly and more consistently than in the past, so that quantitative microstructure imaging is a viable and powerful method of performing phase analysis and extraction of microstructure features.

Despite technological and analytical advances in both XRD and SEM/XMA in the last several decades, each method has its unique advantages and limitations. Applying both methods to characterize a material can often provide a more complete and accurate picture of the phase abundance than can be obtained with either method alone. For example, certification of the SRM portland cement clinker phase abundance is based upon a consensus mean and combined uncertainties of both XRD and SEM/XMA analyses [8].

SEM/XMA can identify the presence, location, and average domain size of a phase that contains calcium as the primary component, without any alkali, sulfur, aluminum, iron, or magnesium. However, that method cannot readily determine whether such a phase is free lime $(\mathrm{CaO})$, portlandite $\left(\mathrm{Ca}(\mathrm{OH})_{2}\right)$, or calcite or aragonite $\left(\mathrm{CaCO}_{3}\right)$. Free lime is often present in clinker because of incomplete conversion of raw 
materials during the clinkering process, but free lime is highly reactive to moisture and carbon dioxide, even at ambient atmospheric levels, and consequently may partially convert to portlandite during grinding or handling. Calcite or aragonite may be present in cement as an additive but may also form from free lime by reaction with carbon dioxide during storage or handling. XRD, especially in combination with thermogravimetric analysis, can help resolve the issue and provide estimates of the relative abundance of free lime, portlandite, calcite, and aragonite because these phases are readily distinguished from each other.

As another example, the mineral arcanite $\left(\mathrm{K}_{2} \mathrm{SO}_{4}\right)$ is typically present in small amounts, usually less than $1 \%$ by mass, in portland cement clinker. Although a small fraction of the solid mass, arcanite reacts rapidly with water, has a major influence on the $\mathrm{pH}$ of the pore solution at early ages, and thereby also influences early-age reaction rates and strength gain. However, the peaks of arcanite in an XRD pattern nearly coincide with those of dolomite $\left(\mathrm{MgCa}\left(\mathrm{CO}_{3}\right)_{2}\right)$, which is sometimes also present in cement as a mineral additive. Determining the relative abundance of arcanite and dolomite by XRD alone is problematic because of the peak overlaps, but SEM/XMA can easily identify and distinguish dolomite and arcanite within the microstructure.

The presence of syngenite, as seen in XRD patterns, suggests possible pre-hydration or cement storage issues as it generally represents a reaction between arcanite (or other alkali sulfates) and gypsum. Phase chemistry $\left(\mathrm{K}_{2} \mathrm{CaSO}_{4} \cdot 2 \mathrm{H}_{2} \mathrm{O}\right)$ would make it appear similar to some of the alkali sulfates in SEM imaging, albeit darker because of the water. The XRD pattern exhibits diagnostic diffraction peaks at 0.571 and 0.316 that are useful in syngenite identification.

These examples illustrate how XRD and SEM/XMA can be used in a complementary way for a more complete quantitative phase analysis of portland cement and portland-cement clinker. The two methods can also be used as a check on each other for consistency. Greater confidence in the results is warranted if both methods provide similar results, while discrepancies between the two methods, when the causes are investigated further, can reveal additional insights about the nature of the material.

This report describes XRD and SEM/XMA imaging and analysis procedures for quantitative phase analysis of portland cement. Emphasis is placed on documenting the procedures and best practices for XRD sample preparation, data collection, and interpretation. A full and detailed description of procedures for SEM/XMA of cementitious materials has been given recently [9], so those procedures will be described much more briefly here. Both XRD and SEM/XMA are used to characterize and compare three commercial portland cements.

Microstructure imaging and image analysis have always had—and likely will continue to have—a partially subjective aspect. Microstructure is often characterized by significant chemical and spatial heterogeneity that can be measured only in a statistical sense. In addition, both an electron beam's interaction with the specimen and image digitization result in volume being homogenized over small elements that cannot be resolved more finely than a single pixel. Consequently, phase assignments can be uncertain for some pixels, especially for those near the boundary between two phases. The fraction of such "borderline" pixels is usually small, but no single objective method is currently available for infallibly assigning their phase identity. Instead, for these cases the user must appeal to several types of possibly inconsistent data about a pixel or pixel grouping, such as its backscattered contrast, X-ray element signal, and location within the microstructure, and arrive at an informed judgment based on experience. Therefore, phrases used in this paper, such as "accurate phase assignment," or "incorrectly assigned pixels" should be understood to mean that the informed judgment of an experienced user is required to make those determinations.

\section{XRD Procedures}

Figure 2 shows an illustration of an X-ray diffractometer, which identifies the major parts and definition of the diffraction angle $2 \theta$, to which this section will refer. Diffraction corresponds to constructive interference of X-rays scattering from a sample, and follows Bragg's law,

$$
\theta=\arcsin \left(\frac{n \lambda}{2 d}\right)
$$




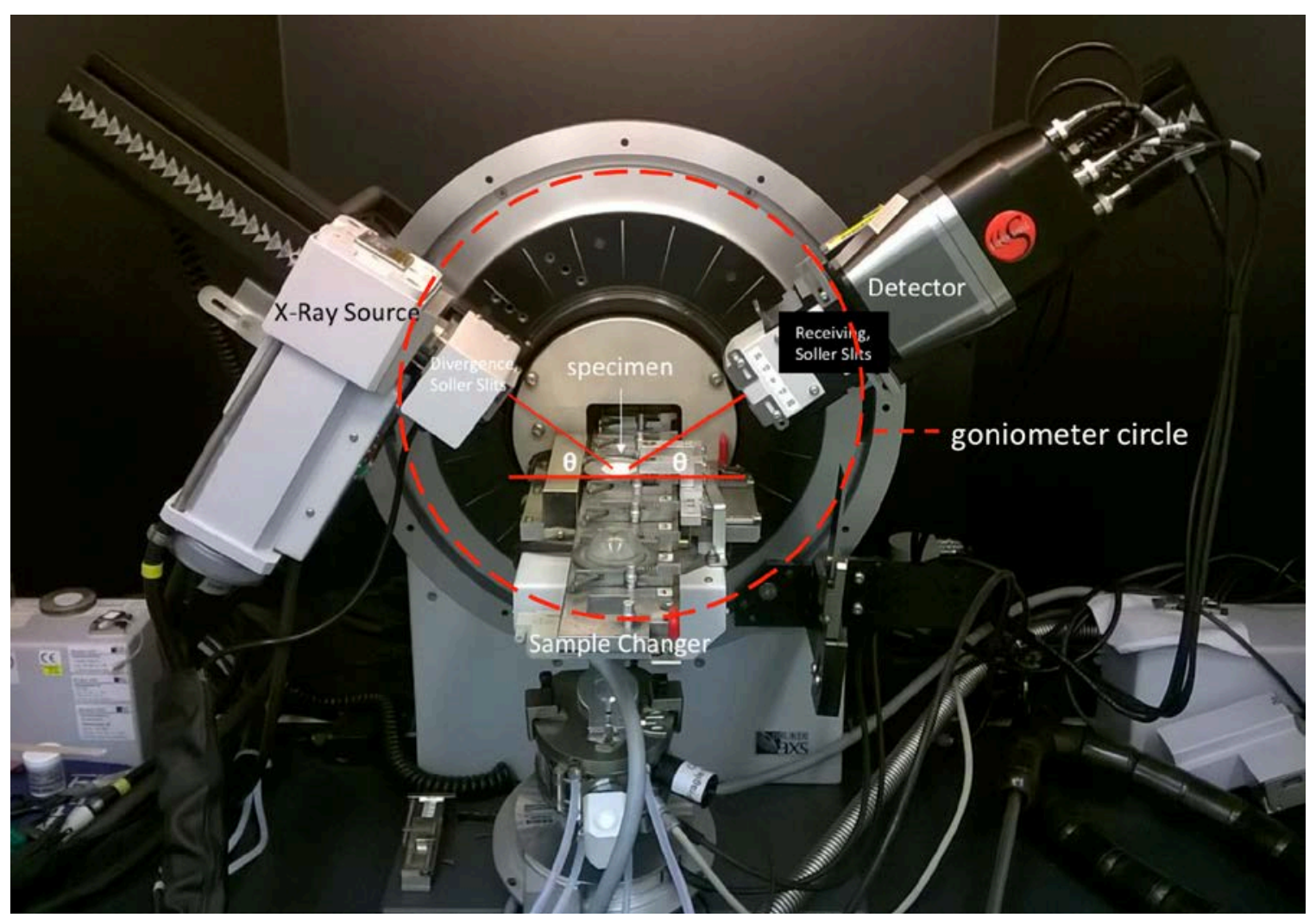

Fig. 2. Illustration of an X-ray diffractometer geometry.

where $\theta$ is the diffraction angle indicated in Fig. 2, $n$ is an integer, $\lambda$ is the wavelength of the X-rays, and $d$ is the distance between two adjacent parallel lattice planes in the crystal structure [10-12].

\subsection{Sources of Error}

A comprehensive assessment by Schreiner et al. [13] of random and systematic errors in XRD analysis concluded that the two most severe errors, by far, are related to improper specimen preparation. According to that study, the greatest source of error is displacement, which means the specimen height is above or below the plane of zero height. Displacement causes a systematic shift in the measured angle $2 \theta$ at which a given Bragg diffraction condition is satisfied, but does not affect the peak intensities significantly.

The second greatest source of error in XRD analysis is preferred orientation. If the powder particles in the specimen are randomly oriented, then the same number of particles, on average, contribute to the diffracted intensity for a given $d$-spacing at a given detector angle $2 \theta$ (see Fig. 2). Consequently, randomly oriented particles produce predictable relative intensities of the different diffraction peaks for a given mineral. Quantitative analysis by Rietveld refinement of a whole diffraction pattern is based on the assumption of randomly oriented particles. Therefore, any departure from random orientation will alter the relative peak intensities from their expected values and therefore may result in a bias in quantitative measurements of phase abundance. Figure 3 shows the bias in diffraction peaks for alite due to preferred orientation. The pattern in black was obtained using a specimen for which preferred orientation was minimized by grinding and careful pressing, and the red pattern was obtained using a coarser specimen and a pressing technique that intentionally induced strong preferred orientation. The effect is evident at $2 \theta=32.1^{\circ}$, where the red peak has significantly greater intensity than in the sample without preferred orientation. In principle, this kind of bias in peak intensities can also be caused by very coarse powders, for which there may not be sufficient crystal orientation sampling to achieve the expected peak intensities. One 


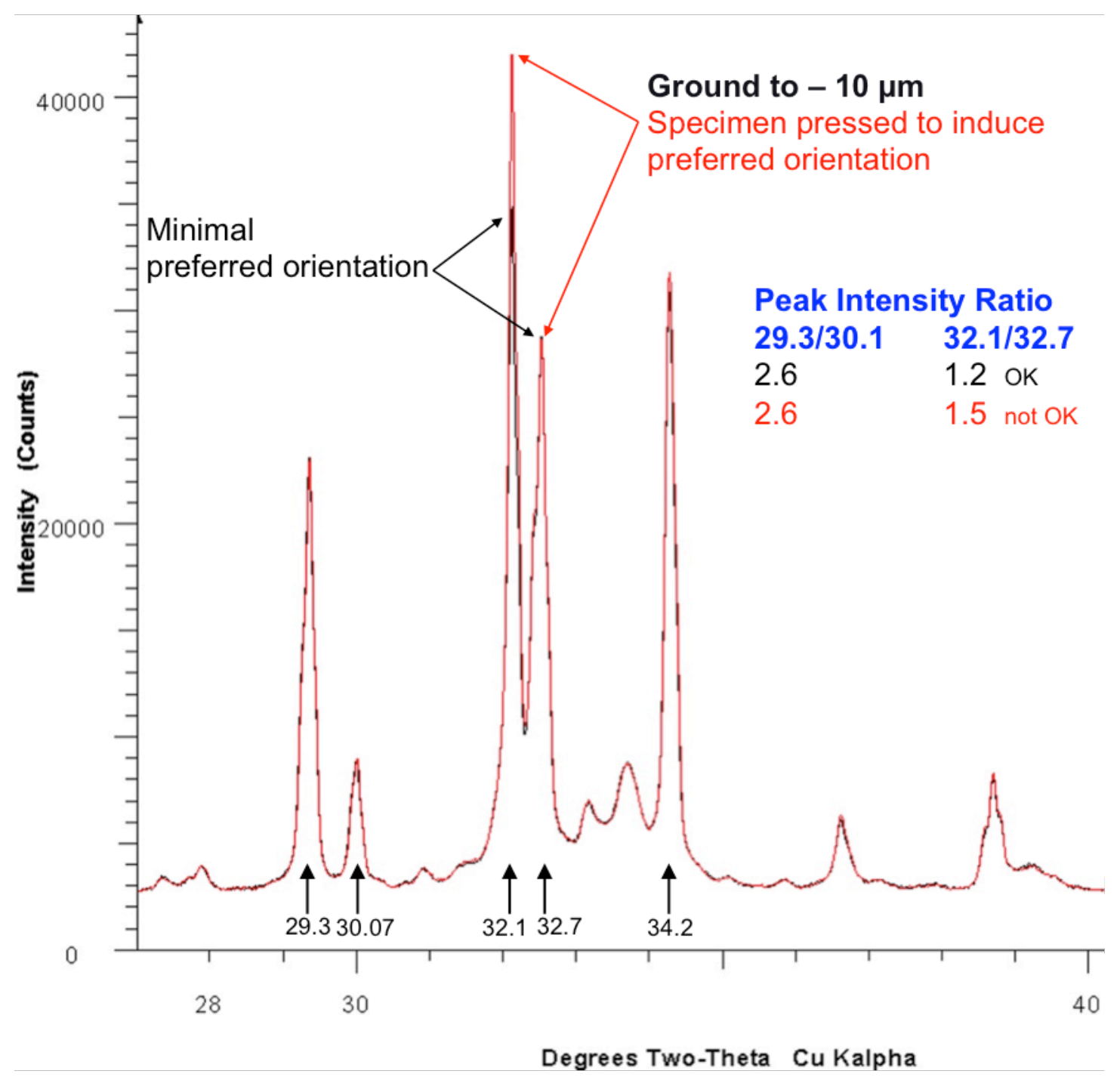

Fig. 3. Part of powder diffraction patterns obtained for alite using a specimen with minimum preferred orientation (black) and intentionally induced preferred orientation (red). For the peaks $32.1^{\circ}$ and 32.7 , the intensity ratio should be about 1.2 , whereas the the red pattern has a peak intensity ratio of 1.5 .

can test for the effect of coarseness by obtaining patterns on the same powder sample that has been removed and repacked in the sample holder; each repacking should produce a different ratio of peak intensities if the bias is caused by coarseness.

Some preferred orientation is difficult to avoid for powders with anisometric grains, such as platelets or needles, because they tend to naturally pack with the particles aligned. Minerals with strong cleavage planes, such as alite, calcite, and gypsum all are susceptible to preferred orientation. Corrections for preferred orientation are available in most XRD analysis software, but they seem to be most effective after steps have been taken to minimize orientation effects by careful specimen preparation, as described in Sec. 2.3.

A third potential source of error in XRD stems from the limited interaction depth of the X-ray beam with the specimen. The interaction depth varies with the X-ray absorptivity of the powder specimen while, for a fixed divergence slit setting, the interaction volume remains constant. A typical interaction depth for cement powder, assuming $2 \theta=40^{\circ}$, is about $15 \mu \mathrm{m}$. For multiphase powders like cement and ground 
clinker, oversampling of one or more phases can easily occur if the phase domains are comparable in size to the interaction depth. This would seem to indicate that powders should be ground to an average size of $10 \mu \mathrm{m}$ or smaller to produce accurate and repeatable diffraction intensities [14]. Achieving this fine a cement powder, for which the as-received particle size is usually $25 \mu \mathrm{m}$ to $40 \mu \mathrm{m}$, may result in damage to the phases and a consequent peak broadening without proper grinding procedure. In-house evaluation, specific to the grinding mill and materials, is needed to determine the amount of grinding required to produce minimal preferred orientation and reproducible peak intensities [15].

The magnitude of all three of these errors can be reduced significantly by proper specimen preparation. Section 2.3 discusses additional aspects of specimen preparation that are most important for obtaining accurate, reliable XRD results.

\subsection{Chemical Extractions}

In multiphase powders such as portland cement or ground clinker, the Bragg condition may be satisfied for different lattice planes in different minerals at the same, or nearly the same, $2 \theta$ angle. The corresponding overlap of peaks are often difficult to deconvolute, and so both qualitative and quantitative analyses are challenging. One solution to this problem is to perform a series of chemical extractions on the powder, by which certain minerals can be selectively dissolved [16]. The extractions cause a relative concentration of the remaining phases and therefore enable improved detection levels. In addition, powders subjected to chemical extraction provide a second set of data that can be used as a check of the XRD patterns obtained using the original powder. XRD patterns using powders with and without chemical extractions can be compared to reduce the influence of peak overlap and thereby facilitate qualitative analysis. Moreover, by calculating the mass loss caused by a given extraction procedure and calculating weighted mass fractions from patterns from different extraction residues one can make quantitative measurements of the phase abundance of minerals that otherwise would be difficult due to peak overlap. The following selective extractions reflect our lab protocols, modified from [16] to provide sufficient residue volume to prepare a specimen mount for XRD.

\subsubsection{Salicylic Acid and Methanol Extraction}

The salicylic acid and methanol (SAM) extraction dissolves alite $\left(\mathrm{C}_{3} \mathrm{~S}^{1}\right)$, belite $\left(\mathrm{C}_{2} \mathrm{~S}\right)$, and free lime $(\mathrm{CaO})$, leaving behind a residue of the tricalcium aluminate $\left(\mathrm{C}_{3} \mathrm{~A}\right)$ and ferrite $\left(\mathrm{C}_{4} \mathrm{AF}\right)$ interstitial phases as well as minor phases including periclase $(\mathrm{MgO})$ and alkali sulfates such as arcanite $(\mathrm{K} \overline{\mathrm{S}})$, thenardite ( $\mathrm{NS}$ ), and langbeinite $\left(\mathrm{KM}_{2} \overline{\mathrm{S}}_{3}\right)$, calcium sulfates (gypsum, bassanite, and anhydrite), and carbonates (calcite and dolomite).

The extraction solution is prepared with $20 \mathrm{~g}$ of salicylic acid in $300 \mathrm{~mL}$ of methanol. Into this solution is stirred a known mass of powdered clinker or cement, usually about $5 \mathrm{~g}$, in a stoppered flask for about 2 $\mathrm{h}$. After allowing the suspended particles to settle for about $15 \mathrm{~min}$, the solution is vacuum filtered using a $0.45 \mu \mathrm{m}$ filter and a Buchner funnel. Finely ground powders can clog the filter and require a long time to be separated. However, very coarse powders may not have sufficient surface area to facilitate the dissolution of phases to be extracted. For stubborn samples, grinding the powder to an average size of $25 \mu \mathrm{m}$ usually provides sufficient surface area while reducing the tendency for clogging. The residue is washed with methanol and dried at a temperature no higher than $65^{\circ} \mathrm{C}$ to preserve the bassanite and gypsum. The residue mass after drying is recorded to calculate the percent insoluble residue, which will subsequently be used to recalculate the phase mass fractions on a whole-cement basis, and the residue is stored in a vacuum desiccator.

Other reagent compositions can be used to achieve alternate phase differentiation in the extraction residues. More detailed descriptions of such extraction methods can be found in the literature, including selective extractions to produce a residue enriched in belite [11, 17].

\footnotetext{
${ }^{1}$ Conventional cement chemistry notation will be used where it is unlikely to cause confusion: $\mathrm{C}=\mathrm{CaO}, \mathrm{S}=\mathrm{SiO}_{2}, \mathrm{~A}=\mathrm{Al}_{2} \mathrm{O}_{3}, \mathrm{~F}=$ $\mathrm{Fe}_{2} \mathrm{O}_{3}, \mathrm{~K}=\mathrm{K}_{2} \mathrm{O}, \mathrm{N}=\mathrm{Na}_{2} \mathrm{O}, \mathrm{M}=\mathrm{MgO}$, and $\overline{\mathrm{S}}=\mathrm{SO}_{3}$.
} 


\subsubsection{Potassium Hydroxide and Sucrose (KOSH)}

The KOSH extraction dissolves the $\mathrm{C}_{3} \mathrm{~A}$ and $\mathrm{C}_{4} \mathrm{AF}$ interstitial phases, leaving a residue of silicates, minor phases, and carbonates. As described in the previous section, grinding the powder to an average particle size of about $25 \mu \mathrm{m}$ provides enough surface area for efficient dissolution while reducing the tendency for clogging the filter afterward.

The extraction solution is prepared with $7.5 \mathrm{~g}$ each of $\mathrm{KOH}$ and sucrose in $75 \mathrm{~mL}$ of distilled water, which is then heated to $95^{\circ} \mathrm{C}$. Into this solution is stirred a known mass of powdered clinker or cement, usually about $2.5 \mathrm{~g}$. After about one minute, the solution is vacuum filtered using a $0.45 \mu \mathrm{m}$ filter and a Buchner funnel. The residue is first washed with $2.5 \mathrm{~mL}$ of distilled water, and then washed with $25 \mathrm{~mL}$ of methanol. The residue is dried at $65^{\circ} \mathrm{C}$. The residue mass after drying is recorded, and the residue is stored in a vacuum desiccator.

\subsection{Specimen Preparation}

Powder XRD specimen preparation involves the packing of powder particles into a cavity holder which is subsequently placed in the diffractometer. Careful preparation and packing of powder, to obtain a smooth top surface that is coincident with the specimen holder to minimize specimen displacement error, is critical to the ease of interpretation of X-ray diffraction patterns for quantitative analysis.

\subsubsection{Grinding}

Reducing powder particle size by grinding can reduce the tendency for preferred orientation by breaking up anisometric particles into smaller, more random shapes. The modified particle size distribution produced by grinding promotes better packing characteristics that lead to smoother surfaces and a reduced likelihood of displacement. Furthermore, portland cement and ground clinker particles are typically composed of multiple phases, so grinding can also promote representative phase sampling by reducing the average phase domain size. In this way, a representative proportion each phase is more likely to fit within the beam interaction volume discussed in Sec. 2.1.

Figure 4 shows the change in cumulative particle size distribution (PSD) of an as-received portland cement as it is wet-ground ${ }^{2,3}$ in isopropyl alcohol for $3 \mathrm{~min}, 6 \mathrm{~min}$, or $9 \mathrm{~min}$. Grinding reduces the median effective particle diameter $\left(d_{50}\right)$ from about $15 \mu \mathrm{m}$ to about $6 \mu \mathrm{m}$, which is significantly less than the interaction depth.

Grinding also improves the homogeneity of the phase distribution and the quality of the top surface of the powder packing. Figure 5 shows optical micrographs of a packed surface of an as-received cement and of the same cement that has been ground until $70 \%$ of the particles have an effective diameter less than $10 \mu \mathrm{m}$. Grinding appears to produce a finder dispersion of dark and light domains, which suggests that the phase distribution is more homogeneous. In addition, although more difficult to perceive in the micrographs, the ground packing has a smoother surface.

\subsubsection{Packing}

As already documented, denser and more homogeneous packings can be produced with finely ground powders, but good technique is still essential to producing a well-packed specimen with a smooth top surface. A high-quality packing requires the correct quantity of powder to be added to, and evenly distributed within, the specimen holder cavity. Determining the correct quantity of powder is a trial-anderror process. A good practice is to first loosely overfill the cavity with powder. The powder can then be evenly distributed within the cavity by lightly and evenly tapping the surface of the powder with the edge

\footnotetext{
${ }^{2}$ McCrone Micronizing Mill, https://www.mccrone.com/mccrone-micronizing-mill

${ }^{3}$ Certain commercial equipment, instruments, or materials are identified in order to specify the experimental procedure adequately. Such identification is not intended to imply recommendation or endorsement by the National Institute of Standards and Technology, nor is it intended to imply that the materials or equipment identified are necessarily the best available for the purpose.
} 


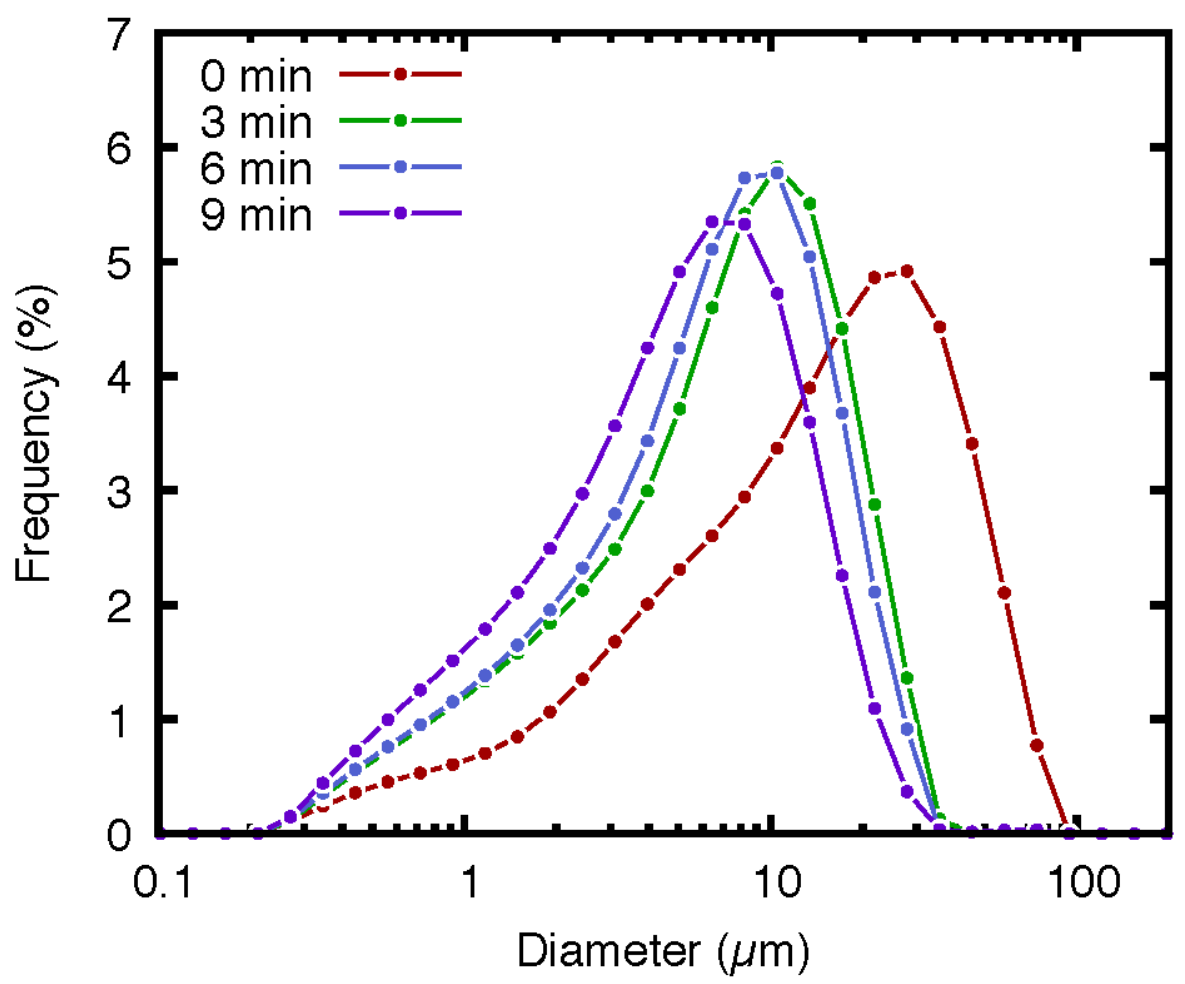

Fig. 4. Differentiated particle size distribution (PSD) of cement powder as a function of wet grinding time. PSD was measured by laser scattering of a dilute particle suspension in isopropyl alcohol. Each point shown is an average of six replicate measurements, with measurement uncertainty on the order of the line marker diameter.

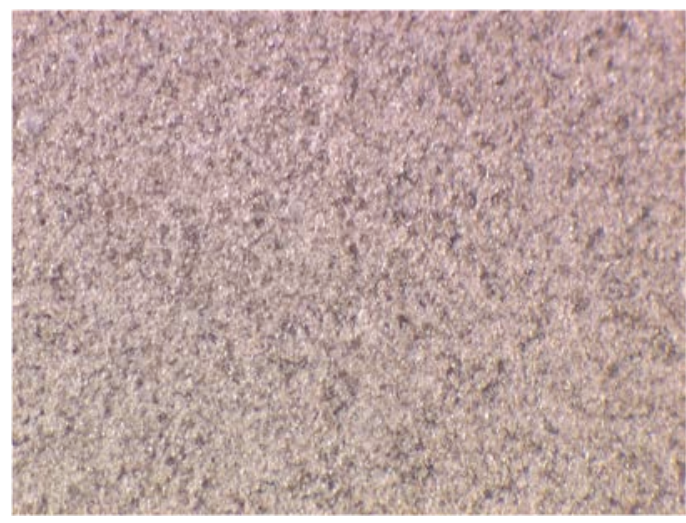

(a)

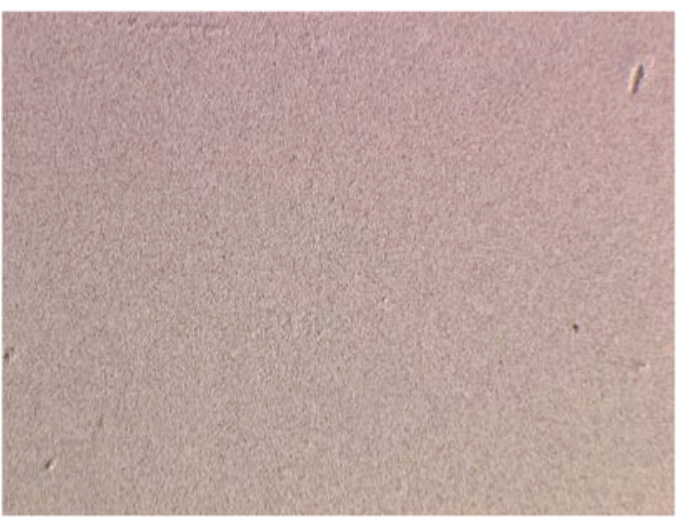

(b)

Fig. 5. Optical micrographs of cement powder packings, each with a field width of $2 \mathrm{~mm}$. (a) As-received cement powder, and (b) the same powder ground until $70 \%$ of the particles had an effective diameter less than $10 \mu \mathrm{m}$. 
of a rigid, straight tool; a glass microscope slide or small lab spatula are good choices. When the cavity has been evenly filled with the powder, the excess powder can be decreased gradually by lightly scraping it away from the top with the tool edge until the top surface is just a little higher, by about $2 \mathrm{~mm}$, than the top of the cavity. Once this is achieved, the tool can be used to evenly scrape away a narrow border of powder around the cavity perimeter; the powder surface within this border should coincide with the top of the cavity, leaving a slightly elevated plateau of powder in the center of the cavity. At this point, a rigid, smooth flat surface can be used to apply vertical pressure to the plateau until the top surface of the entire packing coincides with the top of the cavity. A glass microscope slide provides an ideal surface for this compaction step. It is tempting to slide the compaction tool back and forth horizontally during this step, but this is a poor practice because it increases the likelihood of inducing a surface texture corresponding to preferred orientation. Some practitioners address this by using a rougher tool surface, such as a frosted glass slide or a piece of filter paper, which may reduce the tendency to orient fragments parallel to cleavage planes.

Cement and clinker specimens are sensitive to moisture, so they should be analyzed as rapidly as possible after specimens have been prepared. If some delay between preparation and analysis is unavoidable, the specimens should be stored in a desiccator. Some hydration of the more reactive constituents (e.g., free lime) will inevitably occur. However, small amounts of prehydration may have negligible impact on XRD patterns if the amount of reaction is comparable to the sensitivity limits of the instrument. Free lime will react with moisture to form portlandite, identifiable by a weak and possibly broad diffraction peak at $d$-spacing of $0.490 \mathrm{~nm}\left(18.07^{\circ} 2-\theta\right)$. The portlandite may subsequently carbonate to form calcite; low levels would be difficult to identify because the primary peak of calcite $(0.304 \mathrm{~nm}$, $29.40^{\circ} 2-\theta$ ) overlaps one of the primary alite peaks.

\subsection{Data Acquisition}

Details about the instrumentation for acquiring powder XRD patterns, including the functions of each part, can be found in Ref. [18]. In this paper, a $\theta-\theta$ goniometer is used with a copper X-ray source operating at $35 \mathrm{kV}$ and $45 \mathrm{~mA}$, a $\mathrm{Ni}$ foil to remove $\mathrm{Cu} \mathrm{K} \beta$ radiation leaving $\mathrm{Cu} \mathrm{K} \alpha$ radiation, and a 1-dimensional strip detector. Scans are typically collected from $10^{\circ} 2-\theta$ to $77^{\circ} 2-\theta$ using a step size of $0.017^{\circ}$ at a scan time of $30 \mathrm{~min}$. A $0.4^{\circ}$ divergence slit, $6 \mathrm{~mm}$ receiving slit and $22 \mathrm{~mm}$ detector slit and $4^{\circ}$ Soller slits on the divergent side of the goniometer complete the configuration.

As with any powder sampling method, one should ensure that the sample is representative of the larger material. One way to do this is to acquire replicate data scans, each using fresh mounts of the available powder. If the powder is homogeneous and the mounting scheme is consistent, little difference in the acquired patterns will be observed among the replicates.

\subsection{Phase Identification}

Crystalline components may be identified using the traditional approach of measuring location and relative intensities of the most intense diffraction peaks. An alternative for the complicated cement diffraction patterns is to employ diagnostic characteristics of the composite diffraction pattern, which may be either a single key diffraction peak, or groups of peaks that are typical for a specific mineral, with subsequent confirmation using a powder diffraction pattern database. This approach is facilitated by use of a table for tentative mineral identification, such as Table 1, where the peak locations for resolved, or mostly resolved, diffraction peaks considered useful in their identification are listed along with their d-spacing in nanometer units and angle as degrees $2-\theta$ for $\mathrm{Cu} K \alpha$ radiation. For example, starting from the low angle side of the diffraction pattern, a diffraction peak centered at approximately $11.59^{\circ} 2-\theta$ corresponds to the most intense (100) peak of gypsum. Examining the pattern for additional gypsum peaks at higher angles adds confidence to the identification. Keep in mind that peak positions may vary with phase solid solution and relative intensities may vary depending upon the degree of randomness of the specimen mount. The peak location provides a tentative identification, which is subsequently confirmed after comparing to the ICDD database. ${ }^{4}$

${ }^{4}$ ICDD Powder Diffraction Database, International Centre for Diffraction Data, www.icdd.com 
Table 1. Diagnostic diffraction peaks for cement phase identification using $\mathrm{Cu} \mathrm{K} \alpha$ radiation. Numbers in parentheses next to each mineral name is the theoretical intensity as a percentage of the intensity of the most intense peak for that phase in a pure phase pattern.

\begin{tabular}{|c|c|c|}
\hline d-spacing (nm) & $2-\theta$ (degree) & Phase \\
\hline 0.949 & 9.31 & syngenite (40) \\
\hline 0.763 & 11.59 & gypsum (100) \\
\hline 0.725 & 12.20 & ferrite (45) \\
\hline 0.571 & 15.50 & syngenite (55) \\
\hline 0.490 & 18.10 & portlandite (74) \\
\hline 0.428 & 20.72 & gypsum (100) \\
\hline 0.424 & 20.96 & aluminate, cubic (6) \\
\hline 0.418 & 21.26 & arcanite (28) \\
\hline 0.416 & 21.35 & arcanite (23) \\
\hline 0.408 & 21.77 & aluminate, cubic (12) \\
\hline 0.380 & 23.40 & gypsum (17) \\
\hline 0.367 & 24.23 & aphthitalite (20) \\
\hline 0.365 & 24.35 & ferrite (16) \\
\hline 0.350 & 25.45 & anhydrite (100) \\
\hline 0.347 & 25.67 & bassanite (40) \\
\hline 0.331 & 26.89 & langbeinite (95) \\
\hline 0.327 & 27.24 & langbeinite (80) \\
\hline 0.326 & 27.31 & langbeinite (80) \\
\hline 0.323 & 27.64 & langbeinite (100) \\
\hline 0.307 & 29.11 & gypsum (75) \\
\hline 0.304 & 29.36 & alite, triclinic (55) \\
\hline 0.304 & 29.40 & alite, monoclinic (40) \\
\hline 0.303 & 29.48 & Calcite \\
\hline 0.303 & 29.50 & alite, triclinic (65) \\
\hline 0.303 & 29.50 & alite, monoclinic (75) \\
\hline 0.300 & 29.74 & bassanite (80) \\
\hline 0.300 & 29.76 & arcanite (77) \\
\hline 0.299 & 29.91 & alite, triclinic (25) \\
\hline 0.297 & 30.02 & alite, triclinic (18) \\
\hline 0.297 & 30.12 & alite, triclinic (20) \\
\hline 0.296 & 30.16 & alite, monoclinic (25) \\
\hline 0.294 & 30.38 & aphthitalite (75) \\
\hline 0.290 & 30.79 & arcanite (100) \\
\hline 0.289 & 30.96 & arcanite (53) \\
\hline 0.288 & 31.03 & langbeinite (18) \\
\hline 0.288 & 31.05 & dolomite (100) \\
\hline 0.288 & 31.07 & belite, $\beta$ form (21) \\
\hline 0.284 & 31.50 & aphthitalite (100) \\
\hline 0.278 & 32.12 & ferrite (25) \\
\hline 0.272 & 32.98 & aluminate, orthorhombic (65) \\
\hline 0.271 & 33.03 & belite, $\alpha$ form (100) \\
\hline 0.270 & 33.18 & aluminate, cubic (100) \\
\hline 0.269 & 33.25 & aluminate, orthorhombic (100) \\
\hline 0.264 & 33.88 & ferrite $(100)$ \\
\hline 0.241 & 37.36 & free lime (100) \\
\hline 0.211 & 42.93 & periclase (100) \\
\hline
\end{tabular}

\subsection{Data Analysis}

Rietveld refinement is popular because it provides a means to measure pattern intensity and to calculate the best-fit set of patterns based upon modified crystal structure models. The method works by generating a theoretical pattern based on structural models for each of the phases and then compares this calculated pattern to the observed one. Differences between the two can be reduced by altering some of the model parameters. The refinement procedure involves minimizing the sum of the weighted, squared differences between the observed and calculated peak intensities point-by-point over the entire diffraction pattern [19]. The full-pattern approach provides a more precise intensity measurement over that of individual peaks, but each crystalline component must be identified and included in the analysis to ensure proper calculation of the scale (intensity) factors and phase fractions. This approach has been standardized, as described in ASTM C1365 [5, 19]. 
The first step is to establish input files that contain parameters that characterize the instrument configuration and the set of crystal structures for identified phases, together with structure models that best describe the individual phases for each cement. This is accomplished after phase identification using the chemical extraction residue patterns to concentrate different phase groups. The KOSH extraction concentrates the silicate fraction, and the SAM extraction concentrates the interstitial phases. Variables refined for each phase include scale, specimen displacement, background, lattice parameters, and peak shapes. Refinement of the aluminum and iron tetrahedral and octahedral site occupancy fractions in the ferrite phase may be included in refinements for the SAM extraction residue. This refinement of the site occupancy may improve the agreement between the calculated and observed patterns, but the change in quantitative phase estimates are, based on personal experience, typically within the single-lab repeatability standard deviation. Once refined for the selective extraction residues, the phase parameters are fixed to establish starting models that more closely approximate the phases existing in the cements. A correction for preferred orientation of alite is also available in the refinement procedure. However, reducing the alite preferred orientation as much as possible by careful specimen preparation and mounting (Sec. 2.3) is preferred to the application of a correction. Moreover, the published structure model for alite often produces calculated patterns that do not accurately match the peak intensities for alite in real clinker. However, XRD measurements on a reference clinker [8] using that structure model generate alite fractions that are consistent with quantitative microscopy measurements on the same material [20]. Therefore, the alite structure model, even with its imperfections, generates little relative bias in phase fraction estimates.

One potential source of bias in quantitative powder diffraction is microabsorption, where weakly absorbing phases exhibit greater intensities than expected while strongly absorbing phases exhibit lower intensities. Previous calculations of the linear absorption coefficients for the cement phases and that of a mixture from certification of the original SRM 2686a show that ferrite, periclase, and free lime (when present) may be expected to exhibit the greatest estimate uncertainties. Fine grinding reduces microabsorption effects, so corrections are not generally needed when this is done. Ultimately, a comparison of the XRD and SEM data sets developed by two different individuals working independently on SRM 2686a [8] indicated consistent results, with displacement of the means for periclase and ferrite opposite to what one would expect for microabsorption effects [21].

Graphical comparison of the observed versus the calculated pattern, the individual phase patterns, and residual plots are perhaps the best means by which to judge the quality of the fit. Numerical assessment of the fit is made using the chi-squared test, with lower values reflecting better fits. Refinement is stopped when the fit cannot be significantly improved.

\section{SEM/XMA Procedures}

Step-by-step procedures for quantitative phase analysis by SEM/XMA have been given for portland cement clinker in previous reports [9, 22, 23] and so will be described only briefly here.

An electron beam's interaction with the specimen, combined with image digitization, makes it impossible to resolve chemical information on a scale finer than a single pixel. This means that phase distinction can be uncertain for some pixels, especially for those at the boundary between two phases. Although the fraction of such "borderline" pixels is usually small, the user must refer to several types of possibly inconsistent data about such pixels when establishing the training classes used to classify the phases. These data include backscattered electron contrast, X-ray element intensity, and the pixel's location within the microstructure. Resolving the inconsistencies requires the user's informed judgment based on experience. Ultimately, the classification (also called phase segmentation) based on training classes seeks to place each pixel into the class (phase) to which it most likely belongs, and poor segmentations may be improved by adding to the training classes and by post-segmentation processing. These procedures for obtaining and improving phase segmentations are discussed in detail in the following sections. 


\subsection{Specimen Preparation}

Aside from ASTM C183 [24], no guide or standardized procedure is available for sampling clinker or cements to ensure that the SEM sample is representative of the bulk material. Sample splitters or the coneand-quarter method [25] may be used to reduce large-volume samples to representative subsamples. The powder sample is mounted in a medium-viscosity epoxy ${ }^{5}$, to preserve the microstructure, to support the pore and fracture network during cutting and polishing, and to fill the voids to assist in pore identification.

The specimen is cut after the epoxy has cured, using a low-speed diamond saw with ethanol as a cutting lubricant to expose a cross section of the material. The surface is progressively ground and polished using a sequence of silicon carbide papers and diamond pastes, down to $0.25 \mu \mathrm{m}$ roughness. The specimen is cleaned with isopropyl alcohol and carbon coated after the final polish.

Storage in a vacuum desiccator is recommended to avoid reaction with moisture if a significant delay between preparation and data collection is unavoidable. In contrast to XRD, even small amounts of prehydration of free lime or other clinker minerals will be evident by microscopic examination. Prehydration features may be distinguished by their surface being level with the specimen whereas hydration after specimen preparation will stand in high relief due to the substantial volume increase.

\subsection{SEM Imaging}

High-quality images for quantitative analysis can be obtained with the following SEM operating conditions:

1. $12 \mathrm{kV}$ accelerating voltage,

2. $2 \mathrm{nA}$ to $4 \mathrm{nA}$ probe current, adjusted to keep a relatively high X-ray count rate with minimal dead time,

3. a scan rate of $5 \mathrm{~min} /$ frame for an image size of 1024 pixels $\times 768$ pixels to minimize backscattered electron noise,

4. an accumulation of approximately 15 frames for a single field of view to improve the definition of the X-ray (XR) images, and

5. a magnification of $300 \times$, which provides a spatial resolution of approximately $1.0 \mu \mathrm{m} / \mathrm{pixel}$, which is typically on the order of the beam's interaction volume within the specimen.

These settings are a useful starting point to obtain high-quality images, and are judged to represent a balance between fast collection times, a match in resolution of BE images with X-ray map (XR) images, and instrument stability.

The local brightness in a backscattered electron (BE) image is proportional to the average atomic number, $\bar{Z}$, of the phase in that location, and the XR image reflects element spatial distribution over the same field of view. The backscatter coefficient, $\eta$, is a measure of the backscattered electron fraction and, following Goldstein et al. [26], is estimated using the mass fractions and $\eta$ values for each constituent. Table 2 lists phases found in clinker and cement in descending order of their backscattered coefficient and gray intensity. Caution is necessary here because the brightness ranking may change depending upon chemistry variability due to impurities; the exact values are not as important as the general ranking of the phases in the table. The identification of the individual phases also includes supplemental information such as domain shape (e.g., angular or rounded), position within the microstructure (e.g., framework grain, matrix, dispersed phase), and bulk chemistry as described in Table 3.

The BE contrast between alite and belite is relatively strong, but that between belite and cubic tricalcium aluminate is generally too low to rely on contrast to distinguish them. For such phase pairs that have similar BE coefficients, or for phases that have BE coefficients too low to be resolved in the BE image, XR imaging is used to distinguish them based on their composition. For example, periclase and some alkali sulfates often appear black, like the epoxy-filled voids, because of the brightness and contrast settings necessary to make the other phases distinct. Combining the XR and BE images facilitates their discrimination much better than relying on either image alone. Information redundancies also occur that

${ }^{5}$ Epotek 301, Epoxy Technology, Inc., 14 Fortune Drive, Billerica, MA 01821 
Table 2. Cement phases, compositions, densities, average atomic number, and backscattered electron coefficient ranked according to relative SEM BE image brightness [27].

\begin{tabular}{|c|c|c|c|c|c|}
\hline Phase & Composition & Notation & Density $\left(\mathrm{kg} \mathrm{m}^{-3}\right)$ & $\bar{Z}$ & $\eta$ \\
\hline Ferrite & $\mathrm{Ca}_{2}\left(\mathrm{Al}_{\mathrm{x}} \mathrm{Fe}_{1-\mathrm{x}}\right)_{2} \mathrm{O}_{5}$ & $\mathrm{C}_{4} \mathrm{AF}$ & 3770 & 16.65 & 0.186 \\
\hline Free Lime & $\mathrm{CaO}$ & $\mathrm{C}$ & 3320 & 16.58 & 0.188 \\
\hline Alite & $\mathrm{Ca}_{3} \mathrm{SiO}_{5}$ & $\mathrm{C}_{3} \mathrm{~S}$ & 3130 to 3220 & 15.06 & 0.172 \\
\hline Belite & $\mathrm{Ca}_{2} \mathrm{SiO}_{4}$ & $\mathrm{C}_{2} \mathrm{~S}$ & 3280 to 3310 & 14.56 & 0.166 \\
\hline Arcanite & $\mathrm{K}_{2} \mathrm{SO}_{4}$ & $K \bar{S}$ & 2670 & 14.41 & 0.165 \\
\hline Aluminate- $\mathrm{c}^{\mathrm{a}}$ & $\mathrm{Ca}_{3} \mathrm{Al}_{2} \mathrm{O}_{6}$ & $\mathrm{C}_{3} \mathrm{~A}$ & 3040 & 14.34 & 0.164 \\
\hline Portlandite & $\mathrm{Ca}(\mathrm{OH})_{2}$ & $\mathrm{CH}$ & 2260 & 14.30 & 0.162 \\
\hline Aluminate-o ${ }^{b}$ & $\mathrm{Ca}_{3} \mathrm{Al}_{2} \mathrm{O}_{6}$ & $\mathrm{C}_{3} \mathrm{~A}$ & 2560 & 13.87 & 0.159 \\
\hline Aphthitalite & $\mathrm{K}_{3} \mathrm{Na}\left(\mathrm{SO}_{4}\right)_{2}$ & $\mathrm{~K}_{3} \mathrm{~N}_{0.5} \mathrm{~S}_{2}$ & 2700 & 13.69 & 0.158 \\
\hline Syngenite & $\mathrm{K}_{2} \mathrm{Ca}\left(\mathrm{SO}_{4}\right) 2 \mathrm{H}_{2} \mathrm{O}$ & $\mathrm{K}_{2} \mathrm{C} \overline{\mathrm{S}} \mathrm{H}_{2}$ & 2600 & 13.60 & 0.156 \\
\hline Anhydrite & $\mathrm{CaSO}_{4}$ & $C \bar{S}$ & 2980 & 13.41 & 0.154 \\
\hline Bassanite & $2 \mathrm{CaSO}_{4} 0 \cdot 5 \mathrm{H}_{2} \mathrm{O}$ & $\mathrm{C} \overline{\mathrm{S}} \mathrm{H}_{0.5}$ & 2700 & 13.03 & 0.149 \\
\hline Calcite & $\mathrm{CaCO}_{3}$ & $\mathrm{C} \overline{\mathrm{C}}$ & 2710 & 12.56 & 0.142 \\
\hline Gypsum & $\mathrm{CaSO}_{4} 2 \mathrm{H}_{2} \mathrm{O}$ & $\mathrm{C} \overline{\mathrm{S}} \mathrm{H}_{2}$ & 2320 & 12.12 & 0.138 \\
\hline Thenardite & $\mathrm{Na}_{2} \mathrm{SO}_{4}$ & $\mathrm{~N} \overline{\mathrm{S}}$ & 2660 & 10.77 & 0.125 \\
\hline Dolomite & $\mathrm{CaMg}\left(\mathrm{CO}_{3}\right)_{2}$ & $\mathrm{CMC}_{2}$ & 2840 & 10.87 & 0.124 \\
\hline Periclase & $\mathrm{MgO}$ & M & 3580 & 10.41 & 0.121 \\
\hline
\end{tabular}

${ }^{a}$ cubic polymorph

${ }^{\mathrm{b}}$ orthorhombic polymorph

Table 3. Textural and chemical characteristics useful for distinguishing cement phases.

\begin{tabular}{ll}
\hline \multicolumn{1}{c}{ Phase } & \multicolumn{1}{c}{ Identifying Characteristics } \\
\hline $\begin{array}{l}\text { Free Lime } \\
\text { Ferrite }\end{array}$ & Bright BE, rounded crystals, sometimes clustered, strong Ca and no Fe \\
Alite & Bright BE, dendritic to prismatic matrix phase, high Ca, medium Fe and Al \\
Belite & Medium-high BE, euhedral to anhedral crystals, framework grain, strong Ca and Si, minor Mg and Al \\
& Medium BE, rounded crystals, framework grain, sometimes clustered, strong Ca and Si, minor Mg, Al, \\
and weak S & Medium BE, fine to lath-like crystals, matrix phase between ferrite crystals, Ca, Al, Mg, K, Fe, and \\
Aluminate & sometimes Na \\
Arcanite & Medium BE, crystals dispersed along boundaries of matrix and framework grains, high K, S \\
Aphthitalite & Low BE, crystals dispersed along boundaries of matrix and framework grains, high K, Na, S \\
Syngenite & Low BE, K, S, Ca \\
Anhydrite & Ca, S, individual grain, may occur as perimeter phase on gypsum \\
Bassanite & Ca, S, individual grain, not typically resolvable from anhydrite or gypsum \\
Calcite & Ca, no S, K, or Na, individual grain, dark BE \\
Gypsum & Ca, S, no K, Na, individual grains \\
Thenardite & Low BE, crystals dispersed, typically along boundaries of matrix and framework grains, high Na, S \\
Dolomite & Ca, Mg, no Al or S, individual grain \\
Periclase & Low BE, Mg, O, equant to dendritic grains, clustered to dispersed \\
\hline
\end{tabular}


should be reduced or eliminated to improve the phase distinction. For example, the Ca and Si XR image, or a ratio of the two, may be considered for distinguishing the calcium silicate phases. The BE image, however, provides a much better distinction between the calcium silicates and is preferred because XR images have lower resolution and therefore appear grainier and noisier than the BE image. Further details and examples of how SEM images may be combined to render these phases distinct will be discussed in a later section.

\subsection{X-Ray Microanalysis and Imaging}

$\mathrm{X}$-rays are produced as a result of the interaction of the electron beam with the specimen, and they are typically displayed as a set of peaks with a continuous background. The energy-dispersive X-ray analyzer discriminates and counts emitted X-rays based upon their energy.

\subsection{Image Processing}

The next four sections briefly provide guidance for processing the experimentally obtained images and transforming them to a single phase segemented image suitable for quantitative stereological analysis. A more detailed procedure may be found in Stutzman et al. [20]

Image $^{6}$ is used to preview the SEM BE and XR images and to interactively make some adjustments to the background and noise by improving the image quality. The original images are always retained and the File $\rightarrow$ Save As command is used to save a modified image. Appending the filename with an $\mathrm{M}$ to indicate the operation performed on the image indicates that it has been modified. By appending the filename with an operation code, the images will appear together in the directory, allowing for easy viewing of the available images. A TIFF file format is always selected to eliminate any image quality loss with subsequent processing operations.

1. Read images individually or by drag-and-drop with ImageJ.

2. Tile images to arrange all on the monitor (Window $\rightarrow$ Tile)

3. Assign a gray lookup table (LUT) to each image (Image $\rightarrow$ Lookup Table $\rightarrow$ Grays)

4. Adjust each image's brightness and contrast to assess the noise associated with low element concentration or the background (image noise): Image $\rightarrow$ Adjust $\rightarrow$ Brightness Contrast

5. Subtract background noise with operation (Process $\rightarrow$ Subtract) using the preview check box in the Subtract operation window to interactively select the noise level. When acceptable, select $O K$.

6. Clean up any noise by filtering. The Despeckle and the Remove Outliers commands under Process $\rightarrow$ Noise can be applied to remove isolated pixels or small pixel groups. The median filter (Process $\rightarrow$ Filters $\rightarrow$ Median) or the Thresholded Blur will also work well to reduce image noise while retaining edge details. Apply any filtering lightly as edge blur may result in problems during the segmentation phase. Save the modified image using File $\rightarrow$ Save As $\rightarrow$ TIFF, appending the original file name with an " $\mathrm{M}$ " to indicate this file has been modified, so that the original is not over-written.

7. Use MultiSpec ${ }^{7}$ to generate a segmented, indexed image where each pixel is uniquely assigned to the class it most likely belongs based upon a user-developed training set of data. An abbreviated set of steps, which will be detailed below include (a) reading image files, (b) linking files, (c) designating phase classes, (d) establishing training fields for each class, (e) selecting a classification algorithm, (f) evaluating the classification, (g) saving the project, and (h) saving the classified image as an indexed, segmented TIFF file. This image file will then be used for the image analysis for determining phase area fraction, phase mass fraction, and phase perimeter

\footnotetext{
${ }^{6}$ http://imagej.nih.gov/ij/

${ }^{7}$ https://engineering.purdue.edu/ biehl/MultiSpec/
} 
fraction. The resulting image and phase-related data are useful characteristics of the microstructure and for introduction into simulation models like VCCTL [28, 29] or THAMES [30].

8. In Multispec, read initial image as a multispectral type (File $\rightarrow$ Open Image), and check "multispectral type" box. Under "Multispectral Display Specifications" accept the defaults with the exception of the "Enhancement" section, where you can opt to not change the image (the usual), clip it on the low and high end, or user selected clipping.

9. Link the set of X-ray images deemed useful in making a segmentation: File $\rightarrow$ Open Image. Note: This operation requires selecting "Link to active image window" from the drop-down box. Select the X-ray images by clicking on them individually. Remember to select the modified ones (M). Use a standard image sequence so that the exact image source in the virtual linked files (BEI, $\mathrm{Al}, \mathrm{Mg}, \mathrm{K}, \mathrm{Na}, \mathrm{S}$ ) can easily be recalled or write it down. They can be named later if necessary and excluded in the classification if desired. Click on the Cancel button to complete the linking.

10. Save the image set (Processor $\rightarrow$ Reformat $\rightarrow$ Rectify Image)

Use the window defaults (one could attempt to correct any displaced images here if needed), make sure the path is correct and provide a name, retaining the .LAN extension. Use the original file name to keep them together in a listing. If you do not include the extension, the file will be written without one and will not be recognized for future Read operations.

11. Open the .LAN image set for review, assigning classes and training fields, and classification (File $\rightarrow$ Open Image)

A window labeled "Multispectral Display Specifications" will appear, where color channels (R G B) can be assigned and the images enhanced by clipping or transformation. At NIST, enhancements are performed using ImageJ because Multispec seems to apply a single set of operations to each image. View the image using different channel/color combinations. The most useful are:

- $\quad \mathrm{BE}, \mathrm{Mg}, \mathrm{Al}$ - alite, belite, aluminate, ferrite, periclase, lime, calcite, dolomite, voids

- BE, K, S - alkali sulfates, calcium sulfates

12. Establish training classes (Processor $\rightarrow$ Statistics)

Accept the defaults in the "Set Project Options" window by clicking $O K$.

In the new Project window you will see a Class Designation at the top. Enter the list of classes here by boxing in a region in the image for each, selecting "Add to List" and providing a name. The classes are listed based on this sequence and the ultimate index value used for VCCTL or THAMES, following this convention:

$$
\begin{array}{llll}
1=\text { alite } & 2=\text { belite } & 3=\text { aluminate } & 4=\text { ferrite } \\
5=\text { periclase } & 6=\text { arcanite } & 7=\text { aphthitalite } & 8=\text { void }
\end{array}
$$

Record the index designations for later use as some phases will be absent from some materials. Subclasses can be created-for example, alkali sulfate could contain sub-classes arcanite (potassium sulfate) and aphthitalite (potassium, sodium sulfate).

Add training classes then by selecting the class, boxing in more regions, and specifying "Add to List”. The more training pixels, the better the class characteristics are defined.

13. Classify (Processor $\rightarrow$ Classify)

Specify the "Minimum Euclidian Distance" algorithm as it works consistently well. Check the box "Write Classification Results" to Disk File and check the path, retaining the .GIS extension for this image.

Initial quality check is the percent re-assignment of the training set pixels and the quality of the class assignment seen in the .GIS image. The .GIS image is read into Multispec as a Multispectral type image and you will see the class assignments with distinct colors. The colors may be changed by double clicking on the class list followed by setting the color using the color picker.

14. Save the work as a Project

Even if not successful, you can go back and add training fields, delete fields, run alternate classification algorithms, and even exclude specific images to see if it can be improved. 
15. Save the .GIS file as a TIFF file.

This preserves the color assignments for the phases and the index values. Do not save these in the .JPG format as the index values and colors will not be saved. A good practice is to append the file name with a MS suffix, to avoid overwriting the previous files.

16. Clean up any mis-assigned pixels using a surface blur filter that retains edge details. The plugin "Thresholded Blur" works well for this by ignoring pixels that deviate from the mean and by allowing you to specify the kernel size (radius, start with 2 or 3 ), threshold ( 1 or 2 as this is an indexed image and the values differ by 1 ), softness (affects the edge blur) and strength (number of times to apply).

17. Read the TIFF file into ImageJ and write the ASCII Indexed file (File $\rightarrow$ Save As $\rightarrow$ Text Image).

This procedure produces an ASCII file with the phase index values. If needed, you can recall the .GIS file in Multispec or the *MS.TIF file in ImageJ to see which index value corresponds to each phase.

\subsection{Quantitative Image Analysis}

The final result of phase segmentation is a 2D color image that identifies each pixel with an integer index associated with its assigned phase. Quantitative analysis can be performed on such an image to calculate, for example

1. the area fraction of each phase (on a total solids basis)

2. the perimeter fraction of each phase (on a total solid boundary length basis)

3. the spatial distribution of each phase, quantified, for example, by 2-point correlation functions

4. the possible percolation, or connectivity, of each phase in two dimensions

Many, if not all, of these operations can be performed by built-in functions, such as generating a histogram and list from the indexed image or augmenting ImageJ with Java plugins such as the correlation function. However, most of these plugins have been developed and optimized for image processing in other fields, especially biology, and are not well-documented or validated for use with clinker or cement microstructure images. As an alternative, NIST has developed a simple, fast computer program specifically for performing quantitative image analysis on clinker or cement microstructures. The program, called MicroChar [31], is available for Windows or Mac OS X computers, and performs all these calculations with minimal intervention by the user. Installation and use of MicroChar is described in Ref. [31].

\section{Applications to Portland Cement Powders}

This section demonstrates the use of the foregoing procedures to analyze three portland cement powders, which are designated as 3-70, 3-71, and 3-74. ${ }^{8}$ Each of these cements was analyzed by XRD, both with and without selective chemical extractions, and by SEM/XMA.

\subsection{X-ray Diffraction Results}

X-ray powder diffraction analyses include triplicate scans of each sample treatment (bulk cement, KOSH residue, SAM residue) with sample re-packing for each scan. The replication provides multiple estimates of the phase composition for both the individual treatments and the averaged cement composition. A representative set of diffraction data for the three cements are shown in Fig. 6, Fig. 7, and Fig. 8. An initial comparison of the peak intensities between cements provides some insights on their relative compositions. The effects of concentrating specific phase groups is seen by the increased peak intensities in the extraction residue patterns as well as the improved clarity of the simpler residue mixtures.

\footnotetext{
${ }^{8}$ These designations reflect an internal material logging convention at NIST and have no other significance.
} 


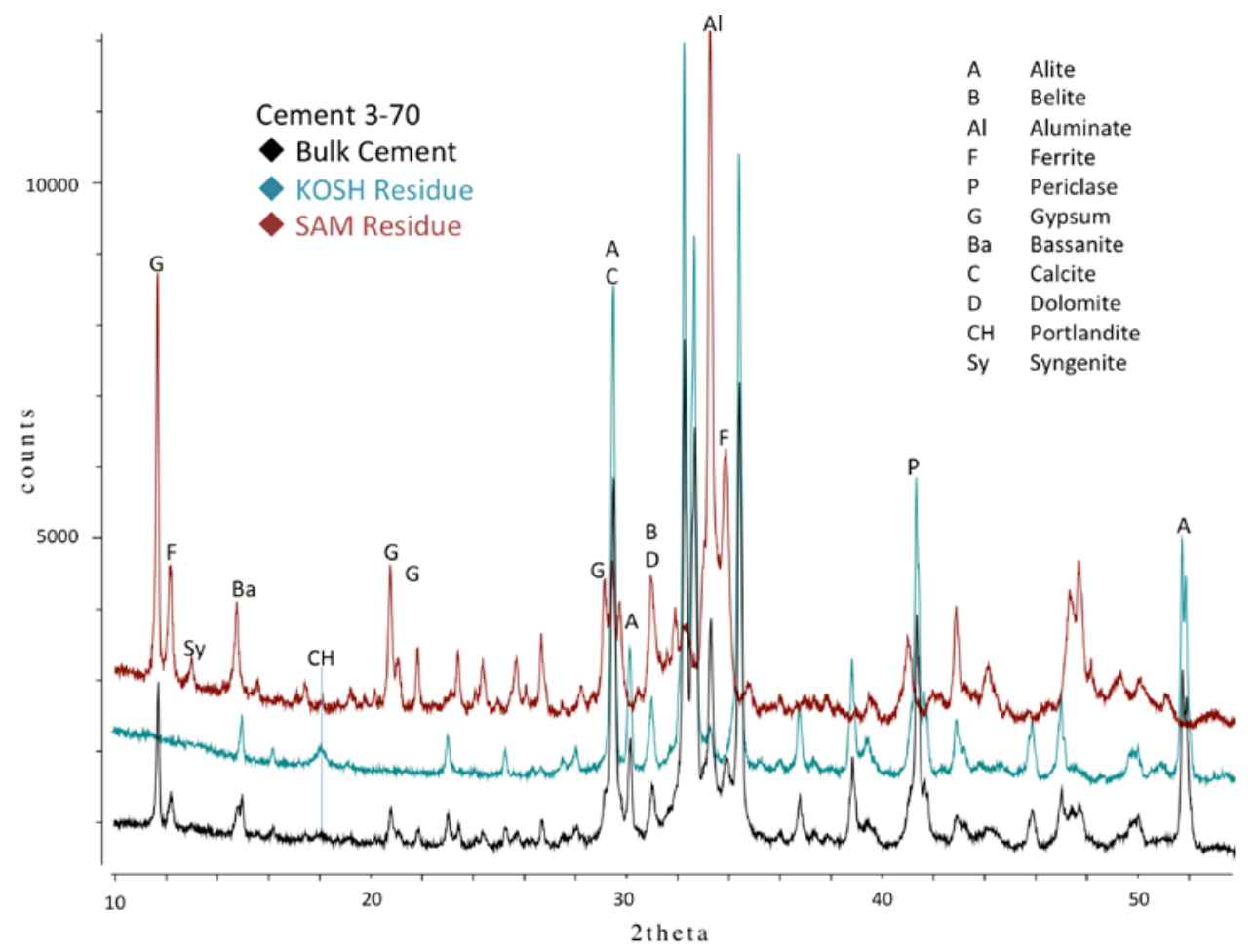

Fig. 6. X-ray powder diffraction patterns for cement 3-70 with phase identifications, with bulk cement (black), KOSH/sugar residue (blue), and SAM residue (red).

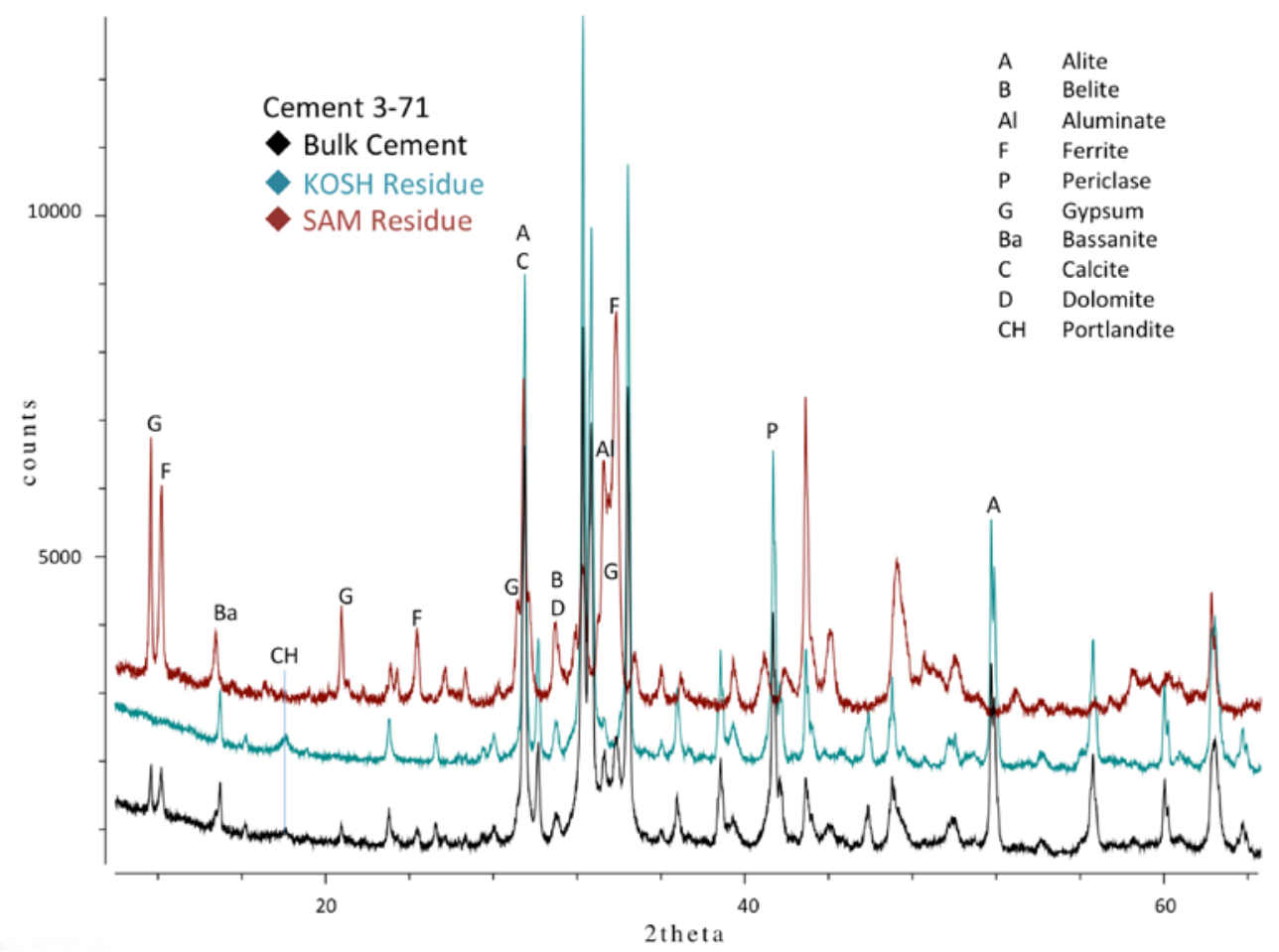

Fig. 7. X-ray powder diffraction patterns for cement 3-71 with phase identifications, with bulk cement (black), KOSH/sugar residue (blue), and SAM residue (red). 


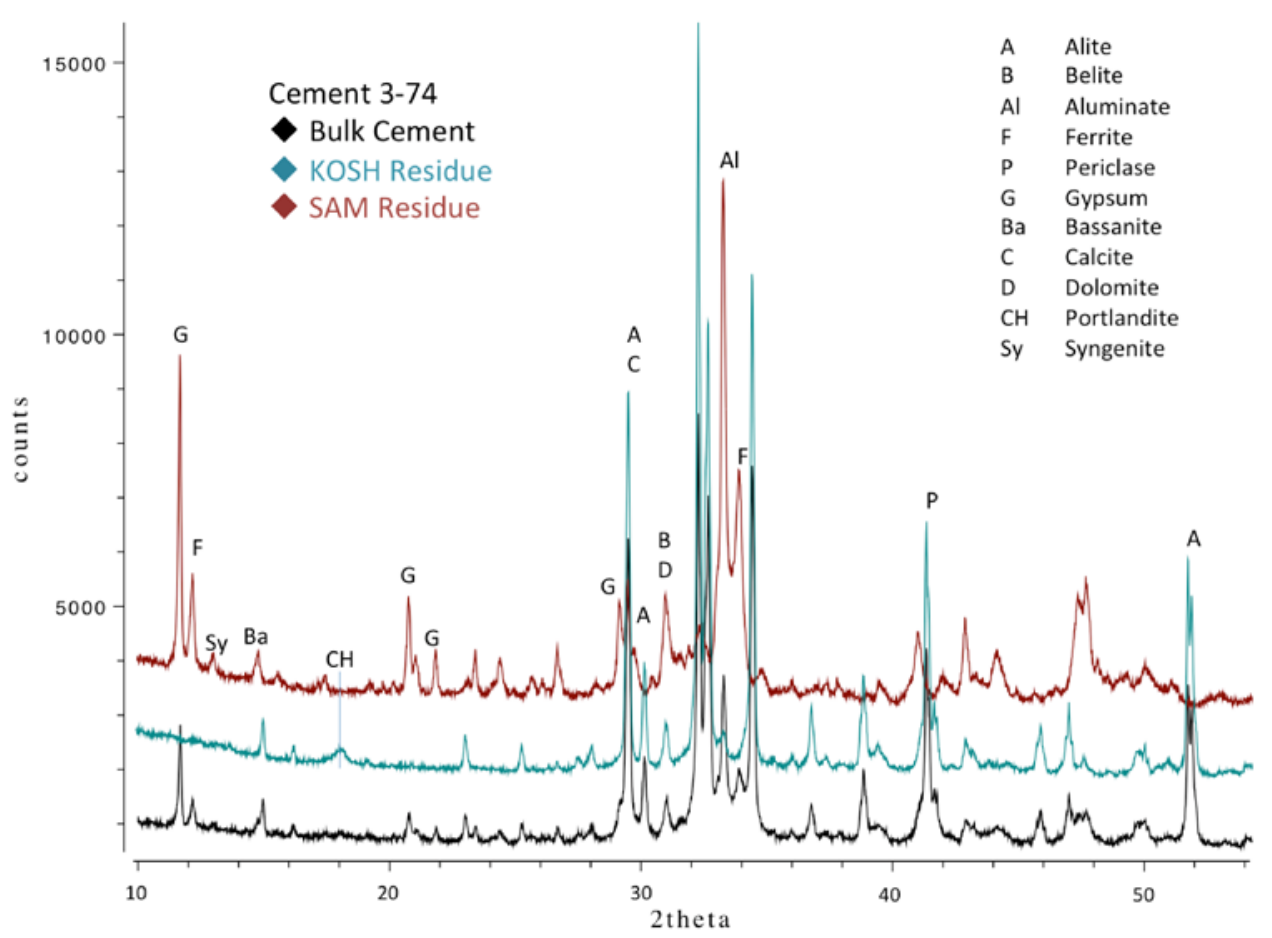

Fig. 8. X-ray powder diffraction patterns for cement 3-74 with phase identifications, with bulk cement (black), KOSH/sugar residue (blue), and SAM residue (red).

For example, cements 3-70 and 3-74 have relatively high aluminate content and relatively low ferrite content compared to cement 3-71, looking at the diffraction peaks for these phases in the $32^{\circ} 2-\theta$ to $36^{\circ} 2-\theta$ region. A diffraction peak shows up in the SAM extraction residue for cements 3-70 and 3-74. Syngenite may form from a reaction between gypsum and one of the forms of potassium sulfate during storage of a cement [32]. It also may form during the selective extraction process or during the filtration of the insoluble residue. Checking the bulk diffraction pattern in these cases suggests that it may be isolated to the SAM extraction, and may be the result of a reaction during this process. Similarly, the presence of a broad diffraction peak around $18^{\circ} 2-\theta$, corresponding to portlandite, is detected from the KOSH residue. Portlandite likely forms during the KOSH extraction procedure itself, which can often be very slow to filter and thereby can alter the phase composition during the final water wash step. For this reason, the KOSH residue quantitative results were not used in the averaging for the overall compositional estimates. Nevertheless, the KOSH extraction residue is useful for examining the silicate phases, including the potential presence of the alpha form of belite.

The SAM extraction residue is particularly helpful as it facilitates phase identifications through concentration of the non-silicate fraction, eliminating the diffraction peak interferences from the silicate phases. Some phases are concentrated by the process, such as the alkali sulfates, which are typically present in low concentrations and otherwise difficult to clearly identify from the bulk cement analysis. This concentration is also helpful in the identification of the calcium sulfate forms, which can affect the hydration characteristics of a cement.

After the qualitative phase identifications, the quantitative results were totaled in two ways: 1) for the extraction residue and 2) recalculated on a whole-cement basis, taking into account the insoluble residue mass as a fraction of the bulk cement. While the phase estimates across sample treatments are generally consistent, alkali sulfate values between the bulk cement and the SAM residue were not. Therefore, the alkali sulfate phase concentration estimates were based only on the SAM residue because they are relatively more concentrated in that residue and less likely to suffer interference from peak overlap. 
Estimates of other phases, such as aluminates, ferrite, periclase, calcium sulfates, and calcium carbonates, represent an averaged value across the six replicates of the two treatments.

\subsection{Microstructure Characterization}

\subsubsection{Backscattered Electron and X-Ray Images}

A representative image field for cement 3-70 is shown in Fig. 9. This image set was collected at $1200 \times$ magnification using a 1024 pixel $\times 768$ pixel image, producing a spatial resolution of $2 \mu \mathrm{m}$ per pixel. This is in excess of that used for routine imaging and was done here to better illustrate the phases. These images were collected simultaneously so they are registered, with the same pixels on each image representing the same region. The brightness is proportional to X-ray counts, and roughly proportional to element concentration. The accompanying color stacks in the figure illustrate the ways in which different phases can be clearly identified. For example, arcanite $(K \bar{S})$ contains only potassium and sulfur, so if the potassium X-ray map is assigned to the green channel and the sulfur X-ray map is assigned to the yellow channel, pixels belonging to arcanite will be white (see Fig. 9(c)) because green and yellow are complementary colors and arcanite, which has a relatively low backscatter coefficient, contributes relatively little to the red $\mathrm{BE}$ channel. Similarly, periclase (MgO) can be identified as bright green domains by assigning $\mathrm{Mg}$ to the green channel, as in Fig. 9(b), because periclase, with low backscatter coefficient, appears dark in BE images. The Al-rich regions shown as dark blue in Fig. 9(b) likely indicate a small quantity of a glassy aluminosilicate slag phase.

\subsubsection{Quantitative Analysis}

The software application MicroChar [31] was used to analyze the indexed image fields produced by the segmentation procedures described in Sec. 3.4. Representative phase-segemented images of the three cements are shown in Figs. 10 through 12, and Tables 4 through 6 show the calculated mean mass percent to be consistent with the XRD results and perimeter percentages of each phase on a total mass and total perimeter basis, respectively. The perimeter percentages illustrate the utility of imaging with the ability to estimate the surface area of the constituent phases. These data may be useful in developing understandings of early-age cement performance given the knowledge of the surface area of each phase initially exposed to the mixing water. The means and uncertainties (1s) were calculated from four to seven segmented images of each cement. A standard error of the mean $s / \sqrt{n}$ along with upper- and lower-confidence limits may be calculated from these data if necessary.

\subsection{Method Comparisons for Phase Abundance}

Tables 7 through 9 summarize and compare the quantitative phase analysis by both methods for each cement. In the tables, the column labeled "XRD" displays the XRD-based mean mass fraction and the standard deviation (s) based on three to five replicate measurements each of the bulk cement and SAM extraction. The values measured for the SAM extraction were renormalized to the original mass of the bulk cement powder. Similarly, the column labeled "SEM/XMA" displays the same information obtained by microstructure analysis, using specific gravities to correct from volume to mass fractions. 


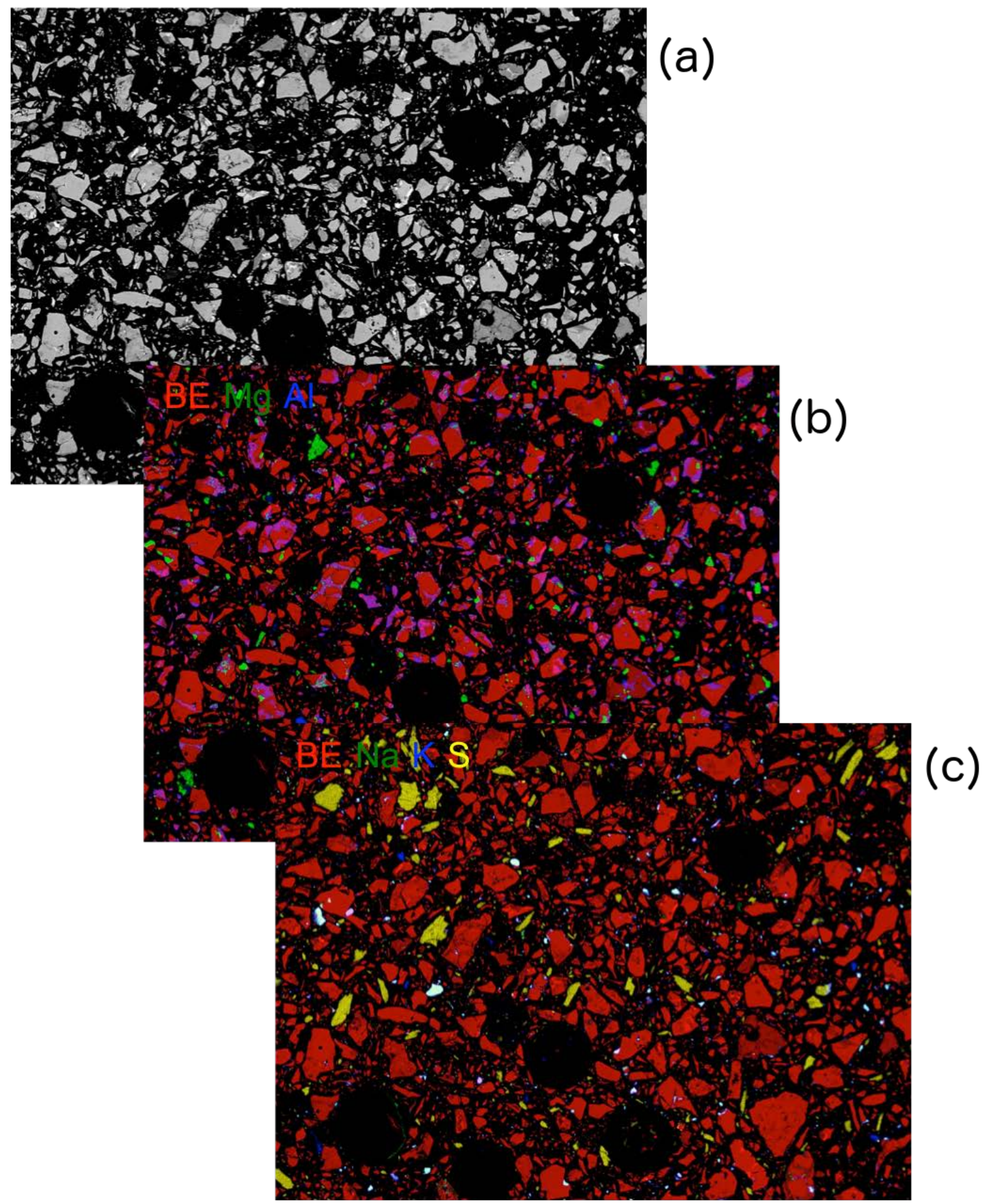

Fig. 9. (a) SEM backscattered electron (BE) image of cement 3-70; (b) color stack of BE image (red channel), Mg distribution (green channel), and $\mathrm{Al}$ distribution (blue channel), in which interstial phases $\mathrm{C}_{3} \mathrm{~A}$ and $\mathrm{C}_{4} \mathrm{AF}$ appear as purple, silicates as red, and periclase as green; (c) color stack of BE image (red channel), Na distribution (green channel), K distribution (blue channel), and S distribution (yellow) channel, in which calcium sulfate carriers and arcanite are visible as yellow and white domains, respectively. Field width is $256 \mu \mathrm{m}$. 

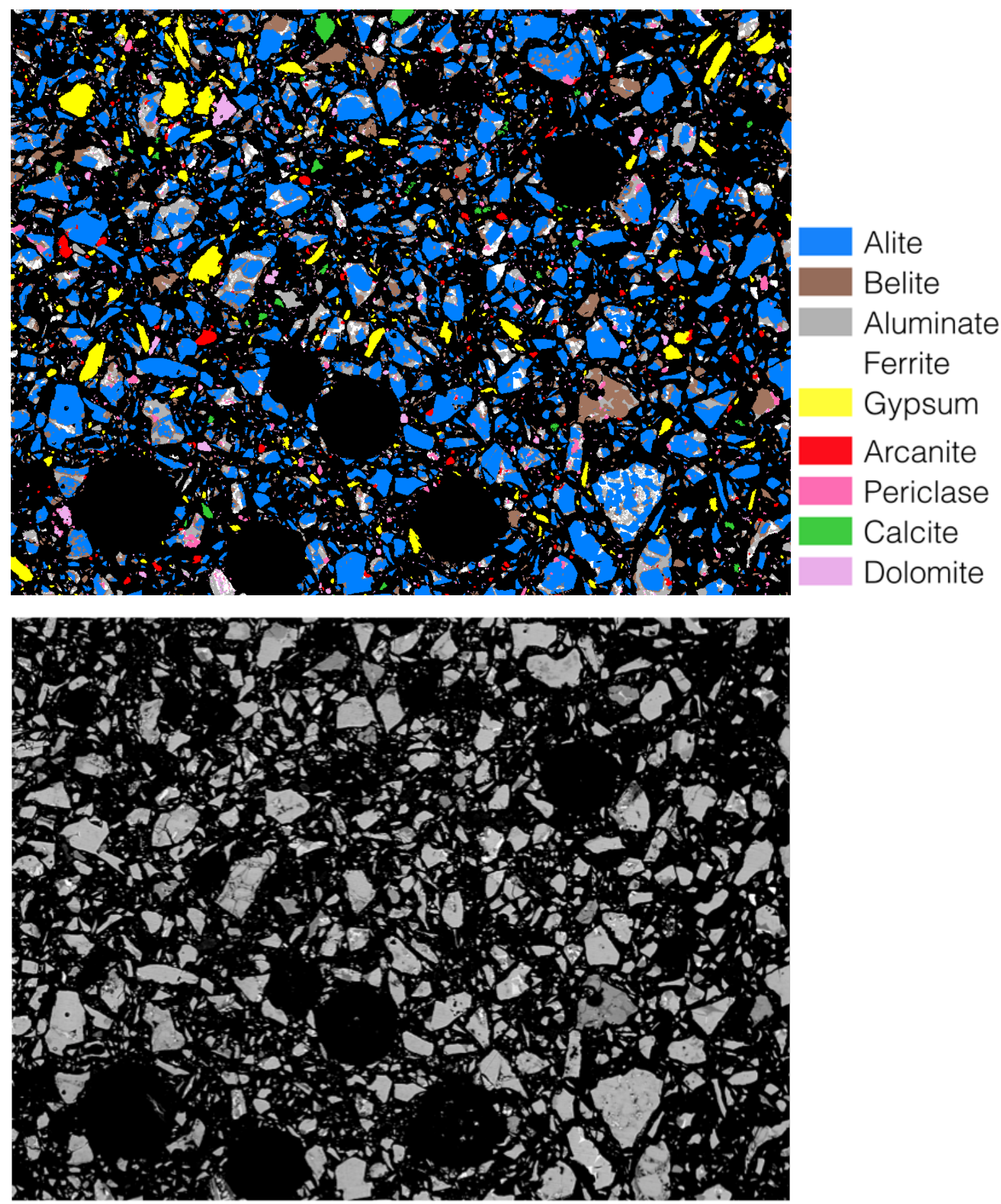

Fig. 10. Final phase-segmented micrograph (top) and original backscattered electron micrograph (bottom) for cement 3-70. Field width is $256 \mu \mathrm{m}$ in each image. 

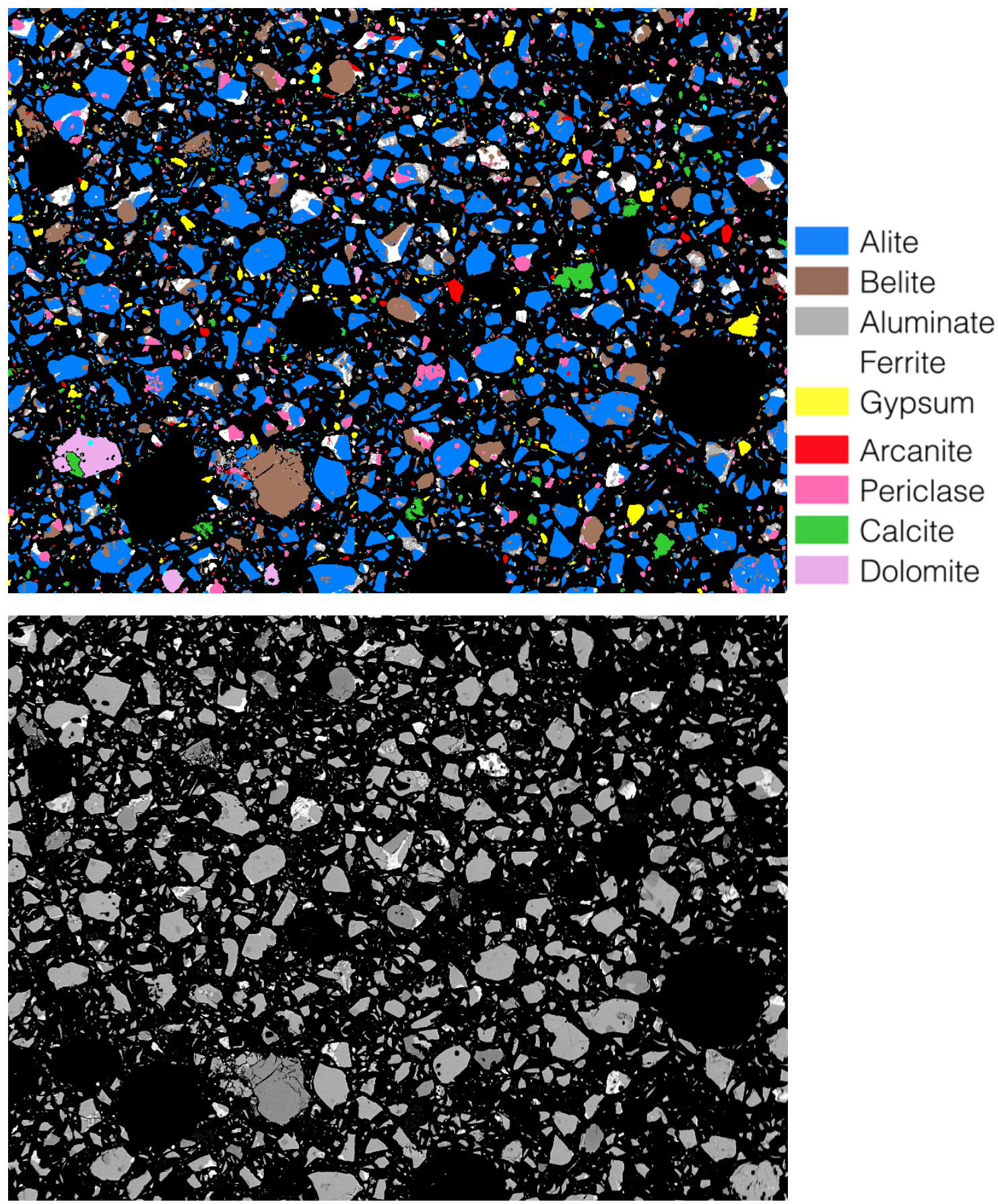

Fig. 11. Final phase-segmented micrograph (top) and original backscattered electron micrograph (bottom) for cement 3-71. Field width is $256 \mu \mathrm{m}$ in each image. 

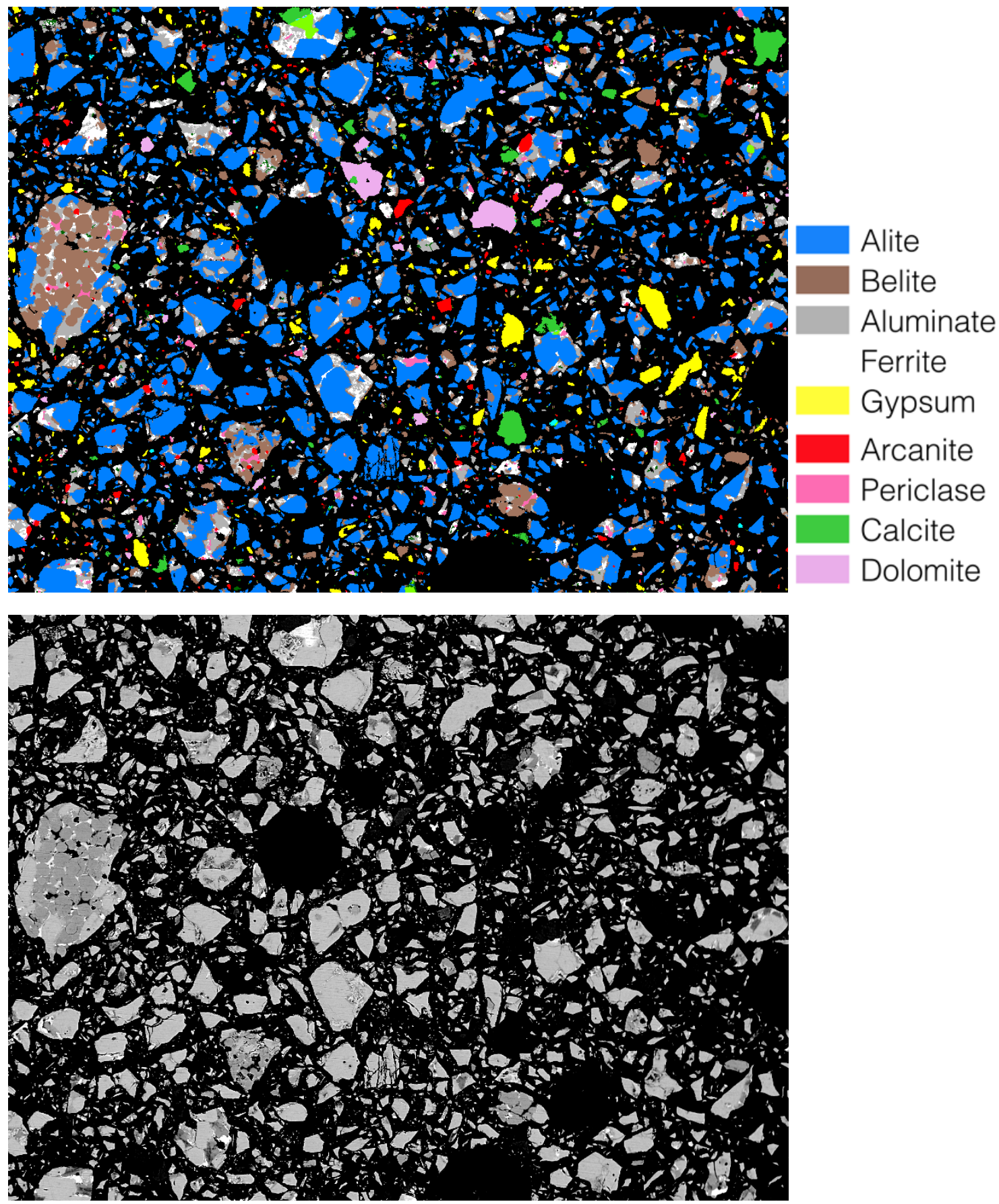

Fig. 12. Final phase-segmented micrograph (top) and original backscattered electron micrograph (bottom) for cement 3-74. Field width is $256 \mu \mathrm{m}$ in each image. 
Table 4. Mean mass and perimeter mass percent of each phase detected by SEM/XMA in cement 3-70, expressed as percentages of total mass. Variability is reported as one standard deviation (s) based on six image fields.

\begin{tabular}{llcccc}
\hline Phase & \multicolumn{2}{c}{ Mass Percent } & \multicolumn{2}{c}{ Perimeter Percent } \\
& $\mathrm{n}$ & Mean & \multicolumn{2}{c}{ Mean } & 0.9 \\
\hline Alite & 6 & 54.9 & 1.5 & 39.8 & 1.0 \\
Belite $_{\text {Aluminate }}^{\mathrm{a}}$ & 6 & 14.0 & 1.1 & 17.5 & 0.5 \\
Ferrite $_{\text {Periclase }}$ & 6 & 10.8 & 0.7 & 11.8 & 1.0 \\
Alkali Sulfate $^{\mathrm{b}}$ & 6 & 6.3 & 1.6 & 4.0 & 0.6 \\
Gypsum $^{\mathrm{c}}$ & 6 & 2.3 & 0.3 & 2.3 & 0.5 \\
Calcite $_{\text {Dolomite }}$ & 6 & 1.4 & 0.2 & 2.7 & 1.0 \\
Slag & 6 & 5.7 & 1.2 & 8.4 & 0.6 \\
\hline
\end{tabular}

${ }^{a}$ Cubic and orthorhombic polymorphs are grouped together.

${ }^{\mathrm{b}}$ All alkali sulfates (arcanite, thenardite, etc.) are grouped together.

${ }^{\mathrm{c}}$ All forms of calcium sulfate (gypsum, bassanite, anhydrite) are grouped together.

Table 5. Mean mass percents and perimeter fractions of each phase detected by SEM/XMA in cement 3-71, expressed as percentages of total mass and total perimeter, respectively. Variability is reported as one standard deviation (s) based on five image fields.

\begin{tabular}{|c|c|c|c|c|c|}
\hline \multirow[t]{2}{*}{ Phase } & \multirow[b]{2}{*}{$\mathrm{n}$} & \multicolumn{2}{|c|}{ Mass Percent } & \multicolumn{2}{|c|}{ Perimeter Percent } \\
\hline & & Mean & $s$ & Mean & $s$ \\
\hline Alite & 5 & 56.0 & 1.0 & 41.6 & 2.1 \\
\hline Belite & 5 & 17.5 & 1.9 & 18.7 & 1.0 \\
\hline Aluminate $^{a}$ & 5 & 5.6 & 0.3 & 8.2 & 0.6 \\
\hline Ferrite & 5 & 7.1 & 0.4 & 5.6 & 0.1 \\
\hline Periclase & 5 & 5.1 & 1.7 & 4.6 & 1.8 \\
\hline Alkali Sulfate $^{\mathrm{b}}$ & 5 & 0.9 & 0.1 & 2.1 & 0.1 \\
\hline Gypsum $^{c}$ & 5 & 2.5 & 0.2 & 4.5 & 0.4 \\
\hline Calcite & 5 & 2.6 & 0.8 & 3.1 & 0.5 \\
\hline Dolomite & 5 & 0.5 & 0.7 & 0.6 & 0.6 \\
\hline Silica & 5 & 0.9 & 0.7 & 4.9 & 4.7 \\
\hline Slag & 5 & 0.8 & 0.8 & 6.2 & 5.7 \\
\hline
\end{tabular}

${ }^{\mathrm{a}}$ Cubic and orthorhombic polymorphs are grouped together.

${ }^{\mathrm{b}}$ All alkali sulfates (arcanite, thenardite, etc.) are grouped together.

c All forms of calcium sulfate (gypsum, bassanite, anhydrite) are grouped together.

Table 6. Mean mass percents and perimeter fractions of each phase detected by SEM/XMA in cement 3-74, expressed as percentages of total mass and total perimeter, respectively. Variability is reported as one standard deviation (s) based on six image fields.

\begin{tabular}{|c|c|c|c|c|c|}
\hline \multirow[t]{2}{*}{ Phase } & \multirow[b]{2}{*}{$\mathrm{n}$} & \multicolumn{2}{|c|}{ Mass Percent } & \multicolumn{2}{|c|}{ Perimeter Percent } \\
\hline & & Mean & $s$ & Mean & $s$ \\
\hline Alite & 6 & 57.9 & 2.3 & 43.6 & 1.6 \\
\hline Belite & 6 & 12.2 & 1.9 & 16.3 & 1.1 \\
\hline Aluminate $^{\mathrm{a}}$ & 7 & 9.0 & 1.6 & 10.5 & 3.3 \\
\hline Ferrite & 6 & 9.1 & 1.3 & 6.1 & 1.0 \\
\hline Periclase & 6 & 1.5 & 0.4 & 1.6 & 3.5 \\
\hline Alkali Sulfate $^{\mathrm{b}}$ & 6 & 1.7 & 0.3 & 3.5 & 0.5 \\
\hline Gypsum $^{c}$ & 6 & 3.6 & 0.3 & 6.3 & 0.6 \\
\hline Calcite & 6 & 1.1 & 0.4 & 1.5 & 0.5 \\
\hline Dolomite & 6 & 1.9 & 1.1 & 1.7 & 0.3 \\
\hline Silica & 6 & 0.6 & 0.4 & 3.4 & 3.3 \\
\hline Slag & 6 & 1.2 & 0.4 & 5.8 & 4.4 \\
\hline
\end{tabular}

${ }^{\text {a }}$ Cubic and orthorhombic polymorphs are grouped together.

${ }^{\mathrm{b}}$ All alkali sulfates (arcanite, thenardite, etc.) are grouped together.

c All forms of calcium sulfate (gypsum, bassanite, anhydrite) are grouped together. 
Table 7. Mean mass fractions, expressed as percentages of cement mineral phases obtained for cement 3-70 by XRD and SEM/XMA, and with uncertainties reported as one standard deviation (s).

\begin{tabular}{|c|c|c|c|c|c|c|}
\hline \multirow[t]{2}{*}{ Phase } & \multicolumn{3}{|c|}{ XRD } & \multicolumn{3}{|c|}{ SEM/XMA } \\
\hline & $\mathrm{n}$ & Mean & $s$ & $\mathrm{n}$ & Mean & $S$ \\
\hline Alite & 3 & 53.5 & 0.3 & 6 & 54.9 & 1.5 \\
\hline Belite & 3 & 14.9 & 0.1 & 6 & 14.0 & 1.1 \\
\hline Aluminate-c ${ }^{\mathrm{a}}$ & 6 & 5.3 & 0.3 & 6 & $10.8^{\mathrm{a}}$ & 0.7 \\
\hline Aluminate-o $^{\mathrm{b}}$ & 6 & 4.5 & 0.7 & 6 & & \\
\hline Ferrite & 6 & 8.0 & 0.3 & 6 & 6.3 & 0.6 \\
\hline Periclase & 6 & 1.7 & 0.2 & 6 & 2.3 & 0.3 \\
\hline Arcanite & 6 & 0.1 & 0.1 & 6 & $1.4^{\mathrm{c}}$ & 0.2 \\
\hline Aphthitalite & 6 & 0.3 & 0.0 & 6 & & \\
\hline Syngenite & 6 & 1.7 & 0.0 & 6 & & \\
\hline Gypsum & 6 & 3.3 & 0.1 & 6 & $5.7^{c}$ & 1.2 \\
\hline Bassanite & 6 & 1.9 & 0.8 & 6 & & \\
\hline Calcite & 6 & 2.1 & 0.2 & 6 & 1.7 & 0.5 \\
\hline Quartz & 6 & 0.5 & 0.2 & 6 & 0.0 & 0.0 \\
\hline Dolomite & 6 & 2.2 & 0.2 & 6 & 1.3 & 0.9 \\
\hline
\end{tabular}

${ }^{\text {a }}$ Cubic polymorph; SEM/XMA groups both cubic and orthorhombic polymorphs together.

${ }^{\mathrm{b}}$ Orthorhombic polymorph.

c SEM/XMA groups all alkali sulfates together and groups all calcium sulfates together.

Table 8. Mean mass fractions, expressed as percentages of cement mineral phases obtained for cement 3-71 by XRD and SEM/XMA, and with uncertainties reported as one standard deviation (s).

\begin{tabular}{|c|c|c|c|c|c|c|}
\hline \multirow[t]{2}{*}{ Phase } & \multicolumn{3}{|c|}{ XRD } & \multicolumn{3}{|c|}{ SEM/XMA } \\
\hline & $\mathrm{n}$ & Mean & $s$ & $\mathrm{n}$ & Mean & $s$ \\
\hline Alite & 3 & 58.4 & 0.7 & 5 & 56.0 & 1.0 \\
\hline Belite & 3 & 15.0 & 0.9 & 5 & 17.5 & 1.9 \\
\hline Aluminate-c $c^{a}$ & 6 & 1.6 & 0.2 & 5 & $5.6^{\mathrm{a}}$ & 0.3 \\
\hline Aluminate-o ${ }^{\mathrm{b}}$ & 6 & 2.2 & 0.3 & 5 & & \\
\hline Ferrite & 6 & 10.7 & 0.9 & 5 & 7.5 & 0.4 \\
\hline Periclase & 6 & 3.4 & 0.3 & 5 & 5.1 & 1.7 \\
\hline Arcanite & 6 & 0.3 & 0.1 & 5 & $0.9^{c}$ & 0.1 \\
\hline Aphthitalite & 6 & 0.1 & 0.1 & 5 & & \\
\hline Gypsum & 6 & 1.5 & 0.1 & 5 & $2.5^{\mathrm{c}}$ & 0.2 \\
\hline Bassanite & 6 & 1.7 & 0.2 & 5 & & \\
\hline Calcite & 6 & 3.3 & 0.5 & 5 & 2.6 & 0.8 \\
\hline Quartz & 6 & 0.2 & 0.0 & 5 & 0.9 & 0.7 \\
\hline Dolomite & 6 & 1.1 & 0.2 & 5 & 0.5 & 0.7 \\
\hline
\end{tabular}

${ }^{\text {a }}$ Cubic polymorph; SEM/XMA groups both cubic and orthorhombic polymorphs together.

${ }^{\mathrm{b}}$ Orthorhombic polymorph.

c SEM/XMA groups all alkali sulfates together and groups all calcium sulfates together. 
Table 9. Mean mass fractions, expressed as percentages of cement mineral phases obtained for cement 3-74 by XRD and SEM/XMA, and with uncertainties reported as one standard deviation (s).

\begin{tabular}{|c|c|c|c|c|c|c|}
\hline \multirow[t]{2}{*}{ Phase } & \multicolumn{3}{|c|}{ XRD } & \multicolumn{3}{|c|}{ SEM/XMA } \\
\hline & $\mathrm{n}$ & Mean & $s$ & $\mathrm{n}$ & Mean & $s$ \\
\hline Alite & 3 & 58.9 & 2.8 & 6 & 57.9 & 2.5 \\
\hline Belitea & 3 & 10.8 & 1.3 & 6 & 12.2 & 2.1 \\
\hline Aluminate- $\mathrm{c}^{\mathrm{b}}$ & 6 & 5.5 & 0.2 & 6 & $9.0^{\mathrm{a}}$ & 1.8 \\
\hline Aluminate- $o^{c}$ & 6 & 3.7 & 0.2 & 6 & & \\
\hline Ferrite & 6 & 9.2 & 0.7 & 6 & 9.1 & 1.5 \\
\hline Periclase & 6 & 1.6 & 0.2 & 6 & 1.5 & 0.5 \\
\hline Syngenite & 3 & 1.4 & 0.4 & 6 & $1.7^{\mathrm{d}}$ & 0.3 \\
\hline Aphthitalite & 6 & 0.4 & 0.3 & 6 & & \\
\hline Gypsum & 6 & 3.5 & 0.5 & 6 & $3.6^{\mathrm{d}}$ & 0.3 \\
\hline Bassanite & 6 & 0.9 & 0.5 & 6 & & \\
\hline Calcite & 6 & 1.4 & 0.4 & 6 & 1.1 & 0.5 \\
\hline Quartz & 6 & 0.5 & 0.2 & 6 & 0.6 & 0.4 \\
\hline Dolomite & 6 & 1.9 & 0.2 & 6 & 1.9 & 1.2 \\
\hline
\end{tabular}

${ }^{\text {a }} \mathrm{SEM} / \mathrm{XMA}$ groups both $\alpha$ and $\beta$ polymorphs of $\mathrm{C}_{2} \mathrm{~S}$ together.

${ }^{\mathrm{b}}$ Cubic polymorph; SEM/XMA groups both cubic and orthorhombic polymorphs together.

c Orthorhombic polymorph.

${ }^{\mathrm{d}} \mathrm{SEM} / \mathrm{XMA}$ groups all alkali sulfates together and groups all calcium sulfates together.

The comparison between methods may be more easily grasped by plotting the SEM/XMA mass fractions against the XRD mass fractions, as shown in Figs. 13 through 15. For each cement in these plots, the data fall near the dashed line of equality, especially when the uncertainty of both methods is taken into account, as shown by the horizontal and vertical error bars. Outlying points, which do not touch the line of equality even when including the uncertainty, tend to correspond to phases having very small mass fractions, which are more difficult to detect by either technique.

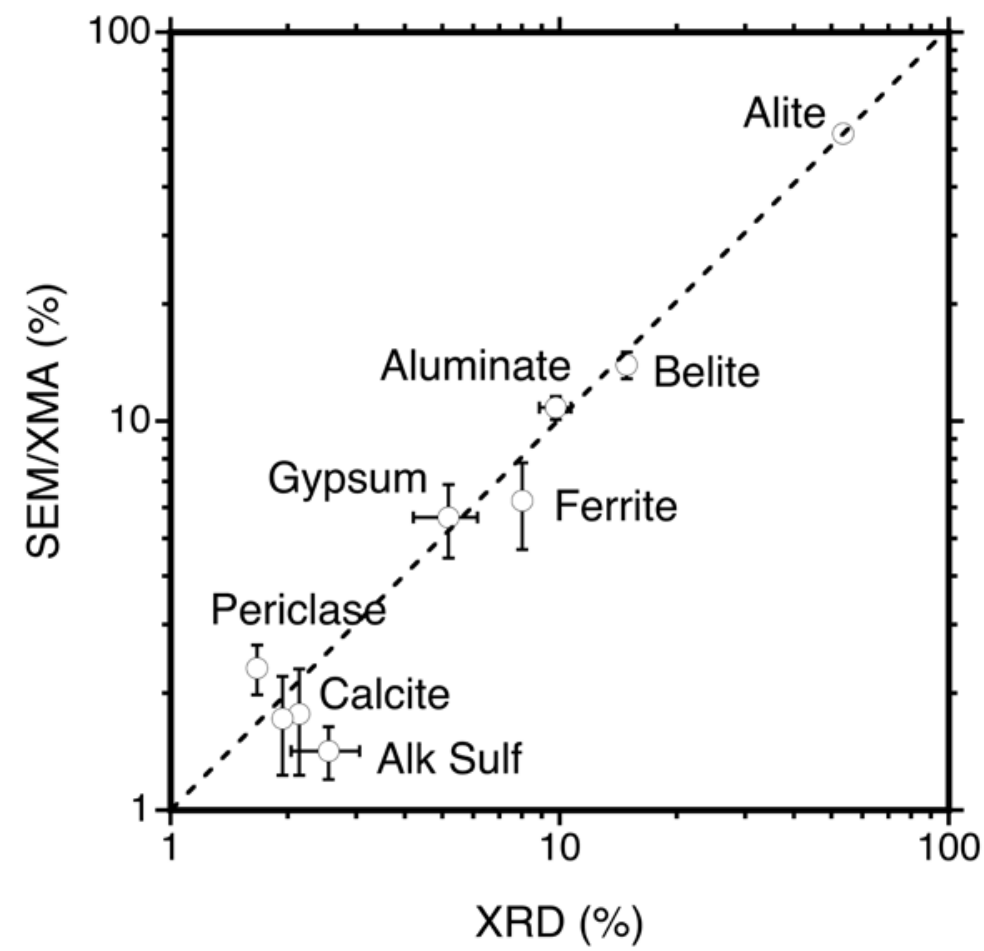

Fig. 13. Comparison of phase abundance in cement 3-70 as measured by SEM/XMA and by XRD. All values are reported as mass percentages on a total solids basis. Error bars represent plus or minus one sample standard deviation as reported in Table 7. 


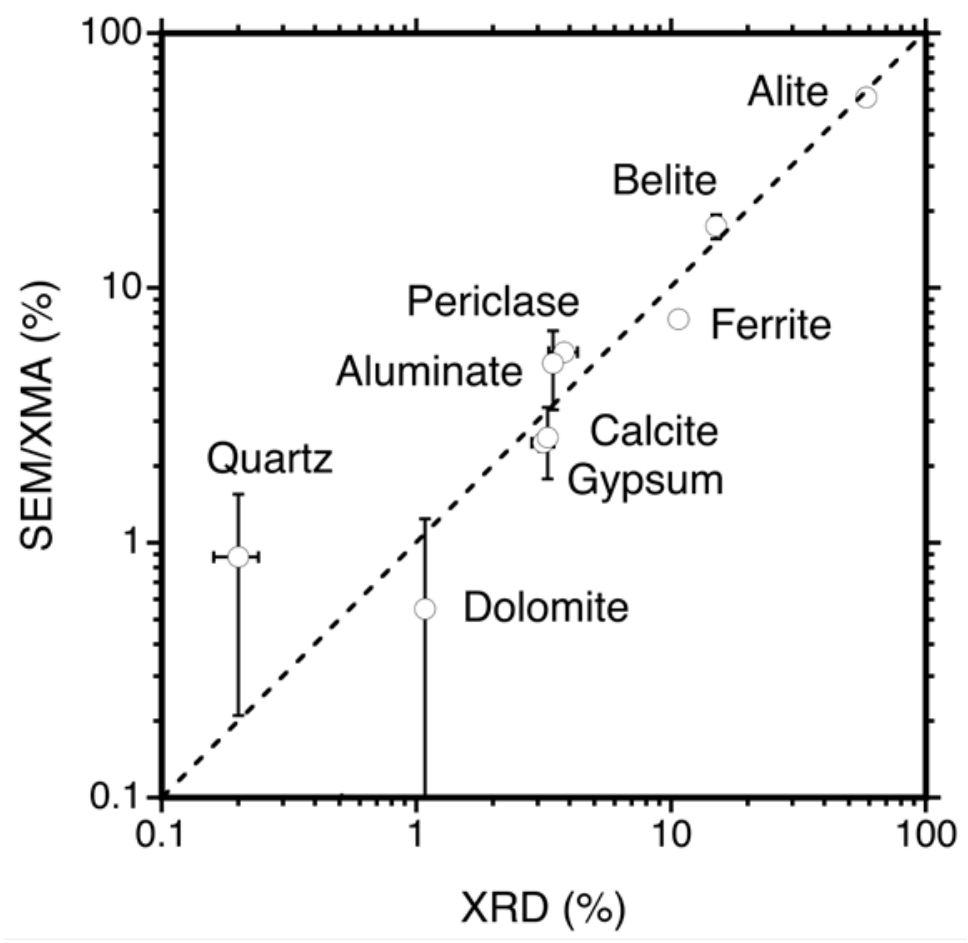

Fig. 14. Comparison of phase abundance in cement 3-71 as measured by SEM/XMA and by XRD. All values are reported as mass percentages on a total solids basis. Error bars represent plus or minus one sample standard deviation as reported in Table 8.

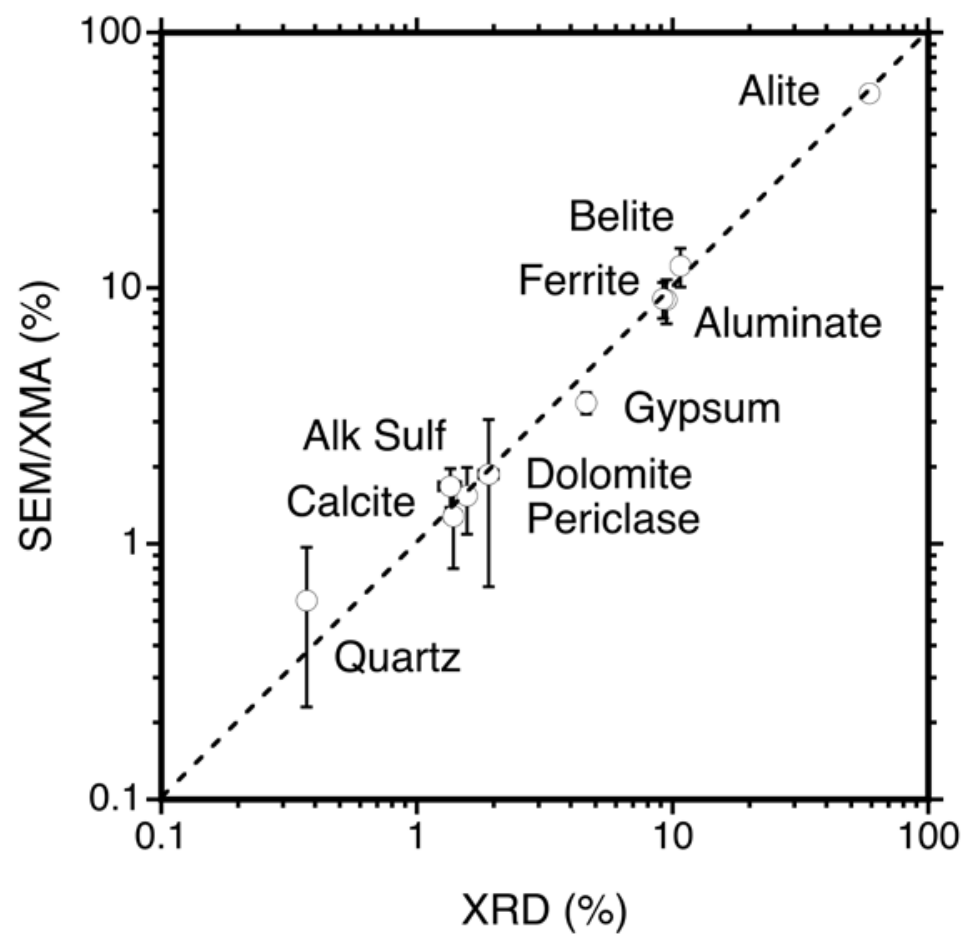

Fig. 15. Comparison of phase abundance in cement 3-74 as measured by SEM/XMA and by XRD. All values are reported as mass percentages on a total solids basis. Error bars represent plus or minus one sample standard deviation as reported in Table 9. 


\subsection{Consensus Means}

The techniques and results provided in this paper potentially can be used to produce the kinds of reference materials that standards committees need for developing standard test methods for composition. Reference materials are generally developed using a consensus from multiple, unique measurement methods. As already described in Sec. 1, each method here has strengths and weaknesses. The XRD method can distinguish polymorphs (cubic and orthorhombic tricalcium aluminate, different calcium sulfate forms such as anhydrite, bassanite, gypsum). The SEM/XMA method can reveal phase texture and phases with small volume occurrence, but can not always make a distinction between polymorphs or the sulfate forms. The goal here is to reconcile the data sets to produce consensus values useful for the cement industry to use in testing and development of quantitative methods for cement phase characterization. The computation of consensus means can be accomplished by using the within-method and between-method variances to determine the confidence in, or weighting of, the average mass fraction for a given phase obtained by SEM/XMA relative to XRD. The consensus mean mass fraction of each phase is the weighted average of the values obtained by each method. In addition, the statistical method calculates the standard uncertainty in the consensus mean values.

Several approaches may be applied to compute consensus means and associated uncertainties based upon results from multiple methods [33]. Here, a consensus method has been chosen that does not weight the result based upon a method's precision or the number of replicate determinations. The intent of using multiple methods is to quantify and include in the overall estimate of uncertainty the systematic biases of the individual methods by using the variation across the methods results.

Two common, but simple, models for estimating a consensus mean and uncertainty are considered first [34]. The Grand Mean is the simplest model that assumes no method effect, and is simply the mean of all the data with a standard t-based confidence interval:

$$
\bar{x}_{\mathrm{GM}} \pm \frac{t_{(1-\alpha / 2, n-1)} S}{\sqrt{n}}
$$

where $\bar{x}_{\mathrm{GM}}$ is the Grand Mean, $t$ is the $t$-value for a given combination of confidence interval, $\alpha$, and number of samples, $n$, and $s$ is the sample standard deviation. In the measurements reported here, the inherently less precise SEM/XMA results have three times the sampling of the XRD measurements. Therefore, the Grand Mean is not the best model, but is merely a starting point.

A second model is the Mean of Means, where a mean and standard deviation are determined separately for each method, and then a mean of those means is calculated along with a confidence interval:

$$
\bar{x}_{\mathrm{MM}} \pm \frac{t_{(1-\alpha / 2, m-1)} S}{\sqrt{m}}
$$

where $\bar{x}_{\mathrm{MM}}$ is the Mean of Means and $m$ is the number of methods used, which is two in this case. This weights the methods equally but does not account for either differences in sample size or within-method variation.

The third method-and the one selected in this report of example consensus values of the composition of each of the three cements - takes unweighted averages of mean values obtained by XRD and SEM/XMA using the Type B on Bias (BOB) approach [35, 36]. The method is designed to handle cases where the number of analytical methods is small (two to five), and the ordinary sample standard deviation is an inadequate estimate of the uncertainty of the systematic effects [37]. The method combines a pooled estimate of within-method uncertainty with a between-method error estimate in quadrature, and multiplies by an expansion factor of $k=2$. The between-method standard error estimate is derived by assuming that different source/method/lab mean estimates distribute uniformly, and then computing a ("betweenmethod") standard error as the standard deviation of the underlying uniform distribution of source means, as $(\max ($ mean $)-\min ($ mean $)) / \sqrt{12}$. 
Tables 10, 11, and 12 show the consensus mean mass fractions of each phase, as a percentage of total solid mass, in cements 3-70, 3-71, and 3-74, respectively. The tables also report the standard uncertainty (i.e., the estimated standard deviation) and the expanded uncertainty (i.e., twice the estimated standard deviation) in the mean values, which for each phase are quite small compared to the mean value. The graphics and statistical analysis code DATAPLOT [33] was used for the consensus calculations found in Tables 10, 11, and 12. A summary of the Dataplot consensus output may be found the appendix.

Table 10. Mass fraction summary statistics by consensus method for cement 3-70.

\begin{tabular}{cccccc}
\hline Phase & $\begin{array}{c}\text { Consensus } \\
\text { Mean (\%) }\end{array}$ & $\begin{array}{c}\text { Within } \\
\text { Method } \\
\text { Uncertainty (\%) }\end{array}$ & $\begin{array}{c}\text { Between } \\
\text { Method } \\
\text { Uncertainty (\%) }\end{array}$ & $\begin{array}{c}\text { Standard } \\
\text { Uncertainty (\%) } \\
k=1\end{array}$ & $\begin{array}{c}\text { Expanded } \\
\text { Uncertainty (\%) } \\
k=2\end{array}$ \\
\hline Alite & 54.18 & 0.32 & 0.39 & 0.51 & 0.34 \\
Belite & 14.41 & 0.23 & 0.26 & 0.33 & 0.69 \\
Aluminate & 10.32 & 0.15 & 0.29 & 0.60 & 0.20 \\
Ferrite & 7.13 & 0.32 & 0.51 & 0.17 & 0.40 \\
Periclase & 1.99 & 0.07 & 0.19 & 0.28 & 0.33 \\
Alkali Sulfates & 1.70 & 0.05 & 0.13 & 0.12 & 0.56 \\
Gypsum & 5.54 & 0.25 & 0.06 & 0.29 & 0.24 \\
Calcite & 1.83 & 0.10 & 0.23 & 0.59 \\
Dolomite & 1.66 & 0.18 & & 0.23 \\
\hline
\end{tabular}

Table 11. Mass fraction summary statistics by consensus method for cement 3-71.

\begin{tabular}{|c|c|c|c|c|c|}
\hline Phase & $\begin{array}{c}\text { Consensus } \\
\text { Mean (\%) }\end{array}$ & $\begin{array}{c}\text { Within } \\
\text { Method } \\
\text { Uncertainty (\%) }\end{array}$ & $\begin{array}{c}\text { Between } \\
\text { Method } \\
\text { Uncertainty (\%) }\end{array}$ & $\begin{array}{c}\text { Standard } \\
\text { Uncertainty (\%) } \\
k=1\end{array}$ & $\begin{array}{c}\text { Expanded } \\
\text { Uncertainty (\%) } \\
k=2\end{array}$ \\
\hline Alite & 57.17 & 0.32 & 0.69 & 0.76 & 1.53 \\
\hline Belite & 16.26 & 0.49 & 0.71 & 0.86 & 1.72 \\
\hline Aluminate & 4.70 & 0.06 & 0.52 & 0.52 & 1.05 \\
\hline Ferrite & 9.12 & 0.10 & 0.91 & 0.92 & 1.84 \\
\hline Periclase & 4.25 & 0.39 & 0.47 & 0.61 & 1.21 \\
\hline Alkali Sulfates & 0.49 & 0.09 & 0.17 & 0.19 & 0.38 \\
\hline Gypsum & 2.81 & 0.04 & 0.20 & 0.20 & 0.40 \\
\hline Calcite & 2.93 & 0.19 & 0.20 & 0.27 & 0.55 \\
\hline Dolomite & 0.81 & 0.15 & 0.16 & 0.22 & 0.44 \\
\hline Quartz & 0.54 & 0.15 & 0.12 & 0.25 & 0.49 \\
\hline
\end{tabular}

Table 12. Mass fraction summary statistics by consensus method for cement 3-74.

\begin{tabular}{|c|c|c|c|c|c|}
\hline Phase & $\begin{array}{l}\text { Consensus } \\
\text { Mean (\%) }\end{array}$ & $\begin{array}{c}\text { Within } \\
\text { Method } \\
\text { Uncertainty (\%) }\end{array}$ & $\begin{array}{c}\text { Between } \\
\text { Method } \\
\text { Uncertainty (\%) }\end{array}$ & $\begin{array}{c}\text { Standard } \\
\text { Uncertainty (\%) } \\
k=1\end{array}$ & $\begin{array}{c}\text { Expanded } \\
\text { Uncertainty (\%) } \\
k=2\end{array}$ \\
\hline Alite & 58.41 & 0.55 & 0.31 & 0.63 & 1.26 \\
\hline Belite & 11.50 & 0.49 & 0.41 & 0.64 & 1.27 \\
\hline Aluminate & 9.11 & 0.36 & 0.05 & 0.36 & 0.73 \\
\hline Ferrite & 9.13 & 0.30 & 0.03 & 0.30 & 0.60 \\
\hline Periclase & 1.55 & 0.09 & 0.01 & 0.09 & 0.19 \\
\hline Alkali Sulfates & 1.76 & 0.06 & 0.05 & 0.08 & 0.16 \\
\hline Gypsum & 4.00 & 0.07 & 0.24 & 0.25 & 0.51 \\
\hline Calcite & 1.34 & 0.10 & 0.03 & 0.11 & 0.21 \\
\hline Dolomite & 1.89 & 0.25 & 0.01 & 0.25 & 0.49 \\
\hline Quartz & 0.43 & 0.08 & 0.01 & 0.08 & 0.16 \\
\hline
\end{tabular}




\section{Summary}

XRD and SEM/XMA are complementary characterization methods, each of which has distinct strengths and weaknesses for quantifying the phase composition of multicomponent materials such as portland cement. XRD is a bulk technique that can potentially quantify each phase, including polymorphs of the same composition, based on crystal structure models. Specimen preparation is relatively easy compared to SEM/XMA, and the results are more precise than SEM/XMA and are representative of the bulk material. Interpretation of XRD patterns is complicated by potential peak overlap among multiple phases, but selective mineral extractions can reduce the uncertainty caused by peak overlap. Furthermore, XRD is unable to assess the nature and composition of any amorphous phases that may be present in the material. SEM/XMA can assess the spatial distribution of phases within the microstructure and does not suffer the uncertainty in phase identification caused by XRD peak overlap. However, specimen preparation is relatively more complicated for SEM/XMA and, in addition, the technique is unable to distinguish phases that are compositionally very similar, such as different hydrated forms of calcium sulfate or mineral polymorphs. Furthermore, SEM/XMA can have lower precision than XRD because of the small sample volumes that are investigated. Therefore, several image fields must be analyzed, depending on the magnification and pixel resolution, to obtain good estimates of phase abundance. Sampling errors also can be reduced by using automated stage motion to obtain any number of partially overlapping images that subsequently can be stitched together to obtain a much larger single image field upon which the analysis can be conducted.

This study has demonstrated how XRD and SEM/XMA can be used together to obtain a better picture of portland cement phase composition than either method alone can provide. The focus has been on describing the methods in sufficient detail so that others can reproduce them in their own laboratories. In addition, the methods have been applied to characterize three portland cement powders. Results from the two methods are consistent, which promotes higher confidence in the results. But beyond that, the Type B on Bias method for calculating consensus means and associated uncertainty estimates provides a quantitative way to account for the different precisions and sampling rates of the two methods so that they can be weighted appropriately in determining the consensus values for each phase. 


\section{Appendix A. Consensus Phase Mass Percentage Analysis for Cement 3-70}

\section{A.1 Alite}

Summary

$\begin{array}{rc}\text { Number of Observations: } & 9 \\ \text { Grand Mean: } & 54.4056 \\ \text { Grand Standard Deviation: } & 1.3918 \\ \text { Total Number of Methods: } & 2 \\ \text { Mean of Method Means: } & 54.1783 \\ \text { SD of Method Means: } & 0.9640 \\ \text { SD of Method Means (wrt to grand mean): } & 1.0162 \\ \text { Within Method (pooled) SD: } & 1.2972 \\ \text { Within Method (pooled) Variance: } & 1.6828 \\ & \\ \text { Method: BOB (Bound on Bias) } & \\ \text { Estimate of Consensus Mean: } & 54.1783 \\ \text { Within Method Uncertainty: } & 0.3205 \\ \text { Between Method Uncertainty: } & 0.3936 \\ \text { Standard Uncertainty }(k=1): & 0.5075 \\ \text { Expanded Uncertainty }(k=2): & 1.0151 \\ \text { Lower 95 \% }(k=2) \text { Confidence Limit: } & 53.1633 \\ \text { Upper 95 \% }(k=2) \text { Confidence Limit: } & 55.1934\end{array}$

\section{Results by method}

\begin{tabular}{cccccc}
\hline $\begin{array}{c}\text { Method } \\
\text { ID }\end{array}$ & $n(i)$ & Mean & Variance & $\begin{array}{c}\text { Standard } \\
\text { Deviation }\end{array}$ & $\begin{array}{c}\text { Standard } \\
\text { Deviation } \\
\text { of the Mean }\end{array}$ \\
\hline XRD & 3 & 53.4967 & 0.0680 & 0.2608 & 0.1506 \\
SEM & 6 & 54.8600 & 2.3286 & 1.5260 & 0.6230 \\
\hline
\end{tabular}




\section{A.2 Belite}

\section{Summary}

$\begin{array}{rc}\text { Number of Observations: } & 9 \\ \text { Grand Mean: } & 14.2589 \\ \text { Grand Standard Deviation: } & 0.9792 \\ \text { Total Number of Methods: } & 2 \\ \text { Mean of Method Means: } & 14.4108 \\ \text { SD of Method Means: } & 0.6446 \\ \text { SD of Method Means (wrt to grand mean): } & 0.6795 \\ \text { Within Method (pooled) SD: } & 0.9265 \\ \text { Within Method (pooled) Variance: } & 0.8583 \\ & \\ \text { Method: BOB (Bound on Bias) } & \\ \text { Estimate of Consensus Mean: } & 14.4108 \\ \text { Within Method Uncertainty: } & 0.2252 \\ \text { Between Method Uncertainty: } & 0.2632 \\ \text { Standard Uncertainty }(k=1): & 0.3464 \\ \text { Expanded Uncertainty }(k=2): & 0.6927 \\ \text { Lower 95 \% }(k=2) \text { Confidence Limit: } & 13.7181 \\ \text { Upper 95 \% }(k=2) \text { Confidence Limit: } & 15.1035\end{array}$

\section{Results by method}

\begin{tabular}{cccccc}
\hline $\begin{array}{c}\text { Method } \\
\text { ID }\end{array}$ & $n(i)$ & Mean & Variance & $\begin{array}{c}\text { Standard } \\
\text { Deviation }\end{array}$ & $\begin{array}{c}\text { Standard } \\
\text { Deviation } \\
\text { of the Mean }\end{array}$ \\
\hline XRD & 3 & 14.8667 & 0.0094 & 0.0971 & 0.0561 \\
SEM & 6 & 13.9550 & 1.1979 & 1.0945 & 0.4468 \\
\hline
\end{tabular}




\section{A.3 Tricalcium aluminate}

\section{Summary}

$\begin{array}{rc}\text { Number of Observations: } & 9 \\ \text { Grand Mean: } & 10.4944 \\ \text { Grand Standard Deviation: } & 0.7769 \\ \text { Total Number of Methods: } & 2 \\ \text { Mean of Method Means: } & 10.3242 \\ \text { SD of Method Means: } & 0.7224 \\ \text { SD of Method Means (wrt to grand mean): } & 0.7615 \\ \text { Within Method (pooled) SD: } & 0.6257 \\ \text { Within Method (pooled) Variance: } & 0.3915 \\ & \\ \text { Method: BOB (Bound on Bias) } & \\ \text { Estimate of Consensus Mean: } & 10.3242 \\ \text { Within Method Uncertainty: } & 0.1543 \\ \text { Between Method Uncertainty: } & 0.2949 \\ \text { Standard Uncertainty ( } k=1): & 0.3329 \\ \text { Expanded Uncertainty }(k=2): & 0.6657 \\ \text { Lower 95 \% }(k=2) \text { Confidence Limit: } & 9.6584 \\ \text { Upper 95 \% }(k=2) \text { Confidence Limit: } & 10.9899\end{array}$

\section{Results by method}

\begin{tabular}{cccccc}
\hline $\begin{array}{c}\text { Method } \\
\text { ID }\end{array}$ & $n(i)$ & Mean & Variance & $\begin{array}{c}\text { Standard } \\
\text { Deviation }\end{array}$ & $\begin{array}{c}\text { Standard } \\
\text { Deviation } \\
\text { of the Mean }\end{array}$ \\
\hline XRD & 3 & 9.8133 & 0.0146 & 0.1210 & 0.0698 \\
SEM & 6 & 10.8350 & 0.5423 & 0.7364 & 0.3006 \\
\hline
\end{tabular}




\section{A.4 Tetracalcium aluminoferrite}

\section{Summary}

$\begin{aligned} \text { Number of Observations: } & 9 \\ \text { Grand Mean: } & 6.8389 \\ \text { Grand Standard Deviation: } & 1.5215 \\ \text { Total Number of Methods: } & 2 \\ \text { Mean of Method Means: } & 7.1325 \\ \text { SD of Method Means: } & 1.2457 \\ \text { SD of Method Means (wrt to grand mean): } & 1.3131 \\ \text { Within Method (pooled) SD: } & 1.3262 \\ \text { Within Method (pooled) Variance: } & 1.7589 \\ & \\ \text { Method: BOB (Bound on Bias) } & \\ \text { Estimate of Consensus Mean: } & 7.1325 \\ \text { Within Method Uncertainty: } & 0.3218 \\ \text { Between Method Uncertainty: } & 0.5085 \\ \text { Standard Uncertainty }(k=1): & 0.6018 \\ \text { Expanded Uncertainty }(k=2): & 1.2036 \\ \text { Lower 95 \% }(k=2) \text { Confidence Limit: } & 5.9289 \\ \text { Upper 95 \% }(k=2) \text { Confidence Limit: } & 8.3361\end{aligned}$

\section{Results by method}

\begin{tabular}{cccccc}
\hline $\begin{array}{c}\text { Method } \\
\text { ID }\end{array}$ & $n(i)$ & Mean & Variance & $\begin{array}{c}\text { Standard } \\
\text { Deviation }\end{array}$ & $\begin{array}{c}\text { Standard } \\
\text { Deviation } \\
\text { of the Mean }\end{array}$ \\
\hline XRD & 3 & 8.0133 & 0.0140 & 0.1185 & 0.0684 \\
SEM & 6 & 6.2517 & 2.4568 & 1.5674 & 0.6399 \\
\hline
\end{tabular}




\section{A.5 Periclase}

\section{Summary}

$\begin{aligned} \text { Number of Observations: } & 9 \\ \text { Grand Mean: } & 2.1011 \\ \text { Grand Standard Deviation: } & 0.4197 \\ \text { Total Number of Methods: } & 2 \\ \text { Mean of Method Means: } & 1.9933 \\ \text { SD of Method Means: } & 0.4573 \\ \text { SD of Method Means (wrt to grand mean): } & 0.4820 \\ \text { Within Method (pooled) SD: } & 0.2860 \\ \text { Within Method (pooled) Variance: } & 0.0818 \\ & \\ \text { Method: BOB (Bound on Bias) } & \\ \text { Estimate of Consensus Mean: } & 1.9933 \\ \text { Within Method Uncertainty: } & 0.0692 \\ \text { Between Method Uncertainty: } & 0.1867 \\ \text { Standard Uncertainty ( } k=1): & 0.1991 \\ \text { Expanded Uncertainty ( } k=2): & 0.3982 \\ \text { Lower 95 \% }(k=2) \text { Confidence Limit: } & 1.5951 \\ \text { Upper 95 \% }(k=2) \text { Confidence Limit: } & 2.3915\end{aligned}$

\section{Results by method}

\begin{tabular}{|c|c|c|c|c|c|}
\hline $\begin{array}{l}\text { Method } \\
\text { ID }\end{array}$ & $n(i)$ & Mean & Variance & $\begin{array}{l}\text { Standard } \\
\text { Deviation }\end{array}$ & $\begin{array}{c}\text { Standard } \\
\text { Deviation } \\
\text { of the Mean }\end{array}$ \\
\hline XRD & 3 & 1.6700 & 0.0003 & 0.0173 & 0.0100 \\
\hline SEM & 6 & 2.3167 & 0.1144 & 0.3382 & 0.1381 \\
\hline
\end{tabular}




\section{A.6 Alkali sulfates}

\section{Summary}

$\begin{aligned} \text { Number of Observations: } & 9 \\ \text { Grand Mean: } & 1.6022 \\ \text { Grand Standard Deviation: } & 0.3296 \\ \text { Total Number of Methods: } & 2 \\ \text { Mean of Method Means: } & 1.6950 \\ \text { SD of Method Means: } & 0.3936 \\ \text { SD of Method Means (wrt to grand mean): } & 0.4149 \\ \text { Within Method (pooled) SD: } & 0.1887 \\ \text { Within Method (pooled) Variance: } & 0.0356 \\ & \\ \text { Method: BOB (Bound on Bias) } & \\ \text { Estimate of Consensus Mean: } & 1.6950 \\ \text { Within Method Uncertainty: } & 0.0466 \\ \text { Between Method Uncertainty: } & 0.1607 \\ \text { Standard Uncertainty ( } k=1): & 0.1673 \\ \text { Expanded Uncertainty ( } k=2): & 0.3346 \\ \text { Lower 95 \% }(k=2) \text { Confidence Limit: } & 1.3604 \\ \text { Upper 95 \% }(k=2) \text { Confidence Limit: } & 2.0296\end{aligned}$

\section{Results by method}

\begin{tabular}{|c|c|c|c|c|c|}
\hline $\begin{array}{l}\text { Method } \\
\text { ID }\end{array}$ & $n(i)$ & Mean & Variance & $\begin{array}{l}\text { Standard } \\
\text { Deviation }\end{array}$ & $\begin{array}{c}\text { Standard } \\
\text { Deviation } \\
\text { of the Mean }\end{array}$ \\
\hline XRD & 3 & 1.9733 & 0.0014 & 0.0379 & 0.0219 \\
\hline SEM & 6 & 1.4167 & 0.0493 & 0.2220 & 0.0906 \\
\hline
\end{tabular}




\section{A.7 Gypsum}

Note: This analysis includes gypsum, bassanite, and anhydrite forms together.

\section{Summary}

$\begin{aligned} \text { Number of Observations: } & 9 \\ \text { Grand Mean: } & 5.510000 \\ \text { Grand Standard Deviation: } & 0.9862302 \\ \text { Total Number of Labs: } & 2 \\ \text { Minimum Lab Mean: } & 5.203333 \\ \text { Maximum Lab Mean: } & 5.663333 \\ \text { Minimum Lab SD: } & 0.07767453 \\ \text { Maximum Lab SD: } & 1.212100 \\ \text { Mean of Lab Means: } & 5.433333 \\ \text { SD of Lab Means: } & 0.3252691 \\ \text { Means (wrt to grand mean): } & 0.3428638 \\ \text { Within Lab (pooled) SD: } & 1.025253 \\ & 1.051143 \\ \text { hin Lab (pooled) Variance: } & \\ & \\ \text { hod: BOB (Bound on Bias) } & \\ \text { Within Lab Uncertainty: } & 0.433333 \\ \text { Between Lab Uncertainty: } & 0.1327906 \\ \text { andard Uncertainty }(k=1): & 0.2816953 \\ \text { Exanded Uncertainty }(k=2): & 0.5633905 \\ \text { ( } k=2) \text { Confidence Limit: } & 4.869943 \\ \text { ( } k=2) \text { Confidence Limit: } & 5.996724\end{aligned}$

\section{Results by method}

\begin{tabular}{cccccc}
\hline $\begin{array}{c}\text { Method } \\
\text { ID }\end{array}$ & $n(i)$ & Mean & Variance & $\begin{array}{c}\text { Standard } \\
\text { Deviation }\end{array}$ & $\begin{array}{c}\text { Standard } \\
\text { Deviation } \\
\text { of the Mean }\end{array}$ \\
\hline XRD & 3 & 5.203333 & 0.006033333 & 0.07767453 & 0.04484541 \\
SEM & 6 & 5.663333 & 1.469187 & 1.212100 & 0.4948378 \\
\hline
\end{tabular}




\section{A.8 Calcite}

\section{Summary}

$\begin{aligned} \text { Number of Observations: } & 9 \\ \text { Grand Mean: } & 1.7944 \\ \text { Grand Standard Deviation: } & 0.4055 \\ \text { Total Number of Methods: } & 2 \\ \text { Mean of Method Means: } & 1.8308 \\ \text { SD of Method Means: } & 0.1544 \\ \text { SD of Method Means (wrt to grand mean): } & 0.1627 \\ \text { Within Method (pooled) SD: } & 0.4175 \\ \text { Within Method (pooled) Variance: } & 0.1743 \\ & \\ \text { Method: BOB (Bound on Bias) } & \\ \text { Estimate of Consensus Mean: } & 1.8308 \\ \text { Within Method Uncertainty: } & 0.1009 \\ \text { Between Method Uncertainty: } & 0.0630 \\ \text { Standard Uncertainty }(k=1): & 0.1190 \\ \text { Expanded Uncertainty }(k=2): & 0.2380 \\ \text { Lower 95 \% }(k=2) \text { Confidence Limit: } & 1.5929 \\ \text { Upper 95 \% }(k=2) \text { Confidence Limit: } & 2.0688\end{aligned}$

\section{Results by method}

\begin{tabular}{cccccc}
\hline $\begin{array}{c}\text { Method } \\
\text { ID }\end{array}$ & $n(i)$ & Mean & Variance & $\begin{array}{c}\text { Standard } \\
\text { Deviation }\end{array}$ & $\begin{array}{c}\text { Standard } \\
\text { Deviation } \\
\text { of the Mean }\end{array}$ \\
\hline XRD & 3 & 1.9400 & 0.0003 & 0.0173 & 0.0100 \\
SEM & 6 & 1.7217 & 0.2439 & 0.4938 & 0.2016 \\
\hline
\end{tabular}




\section{A.9 Dolomite}

\section{Summary}

$\begin{aligned} \text { Number of Observations: } & 9 \\ \text { Grand Mean: } & 1.5211 \\ \text { Grand Standard Deviation: } & 0.8049 \\ \text { Total Number of Methods: } & 2 \\ \text { Mean of Method Means: } & 1.6558 \\ \text { SD of Method Means: } & 0.5716 \\ \text { SD of Method Means (wrt to grand mean): } & 0.6025 \\ \text { Within Method (pooled) SD: } & 0.7441 \\ \text { Within Method (pooled) Variance: } & 0.5537 \\ & \\ \text { Method: BOB (Bound on Bias) } & \\ \text { Estimate of Consensus Mean: } & 1.6558 \\ \text { Within Method Uncertainty: } & 0.1804 \\ \text { Between Method Uncertainty: } & 0.2333 \\ \text { Standard Uncertainty ( } k=1): & 0.2949 \\ \text { Expanded Uncertainty ( } k=2): & 0.5899 \\ \text { Lower 95 \% }(k=2) \text { Confidence Limit: } & 1.0659 \\ \text { Upper 95 \% }(k=2) \text { Confidence Limit: } & 2.2457\end{aligned}$

\section{Results by method}

\begin{tabular}{cccccc}
$\begin{array}{c}\text { Method } \\
\text { ID }\end{array}$ & $n(i)$ & Mean & Variance & $\begin{array}{c}\text { Standard } \\
\text { Deviation }\end{array}$ & $\begin{array}{c}\text { Standard } \\
\text { Deviation } \\
\text { of the Mean }\end{array}$ \\
\hline XRD & 3 & 2.0600 & 0.0037 & 0.0608 & 0.0351 \\
SEM & 6 & 1.2517 & 0.7737 & 0.8796 & 0.3591 \\
\hline
\end{tabular}




\section{Appendix B. Consensus Phase Mass Percentage Values for Cement 3-71}

\section{B.1 Alite}

Summary

\begin{tabular}{rr} 
Number of Observations: & \multicolumn{1}{c}{8} \\
Grand Mean: & 56.8688 \\
Grand Standard Deviation: & 1.5261 \\
Total Number of Methods: & \multicolumn{1}{c}{2} \\
Minimum Method Mean: & 55.9660 \\
Maximum Method Mean: & 58.3733 \\
Minimum Method SD: & 0.7396 \\
Maximum Method SD: & 1.0419 \\
Mean of Method Means: & 57.1697 \\
SD of Method Means: & 1.7022 \\
SD of Method Means (wrt to grand mean): & 1.7546 \\
Within Method (pooled) SD: & 0.9518 \\
Within Method (pooled) Variance: & 0.9060 \\
& \\
Method: BOB (Bound on Bias) & \\
Estimate of Consensus Mean: & 57.1697 \\
Within Method Uncertainty: & 0.3160 \\
Between Method Uncertainty: & 0.6949 \\
Standard Uncertainty ( $k=1):$ & 0.7634 \\
Expanded Uncertainty ( $k=2):$ & 1.5268 \\
Lower 95 \% $(k=$ 2) Confidence Limit: & 55.6428 \\
Upper 95 \% ( $k=$ 2) Confidence Limit: & 58.6965 \\
&
\end{tabular}

\section{Results by method}

\begin{tabular}{|c|c|c|c|c|c|}
\hline $\begin{array}{l}\text { Method } \\
\text { ID }\end{array}$ & $n(i)$ & Mean & Variance & $\begin{array}{c}\text { Standard } \\
\text { Deviation }\end{array}$ & $\begin{array}{c}\text { Standard } \\
\text { Deviation } \\
\text { of the Mean }\end{array}$ \\
\hline XRD & 3 & 58.3733 & 0.5470 & 0.7396 & 0.4270 \\
\hline SEM & 5 & 55.9660 & 1.0855 & 1.0419 & 0.4659 \\
\hline
\end{tabular}




\section{B.2 Belite}

\section{Summary}

\begin{tabular}{rr} 
Number of Observations: & \multicolumn{1}{c}{8} \\
Grand Mean: & 16.5613 \\
Grand Standard Deviation: & 1.9688 \\
Total Number of Methods: & 2 \\
Minimum Method Mean: & 15.0333 \\
Maximum Method Mean: & 17.4780 \\
Minimum Method SD: & 0.8752 \\
Maximum Method SD: & 1.8971 \\
Mean of Method Means: & 16.2557 \\
SD of Method Means: & 1.7286 \\
WD of Method Means (wrt to grand mean): & 1.7818 \\
Within Method (pooled) SD: & 1.6293 \\
Within Method (pooled) Variance: & 2.6546 \\
& \\
Method: BOB (Bound on Bias) & \\
Estimate of Consensus Mean: & 16.2557 \\
Within Method Uncertainty: & 0.4937 \\
Between Method Uncertainty: & 0.7057 \\
Standard Uncertainty $(k=1):$ & 0.8613 \\
Expanded Uncertainty $(k=2):$ & 1.7226 \\
Lower 95 \% $(k=2)$ Confidence Limit: & 14.5331 \\
Upper 95 \% $(k=2)$ Confidence Limit: & 17.9782
\end{tabular}

\section{Results by method}

\begin{tabular}{cccccc}
\hline $\begin{array}{c}\text { Method } \\
\text { ID }\end{array}$ & $n(i)$ & Mean & Variance & $\begin{array}{c}\text { Standard } \\
\text { Deviation }\end{array}$ & $\begin{array}{c}\text { Standard } \\
\text { Deviation } \\
\text { of the Mean }\end{array}$ \\
\hline XRD & 3 & 15.0333 & 0.7660 & 0.8752 & 0.5053 \\
SEM & 5 & 17.4780 & 3.5989 & 1.8971 & 0.8484 \\
\hline
\end{tabular}




\section{B.3 Tricalcium aluminate}

\section{Summary}

$\begin{aligned} \text { Number of Observations: } & 8 \\ \text { Grand Mean: } & 4.9212 \\ \text { Grand Standard Deviation: } & 0.9551 \\ \text { Total Number of Methods: } & 2 \\ \text { Minimum Method Mean: } & 3.7967 \\ \text { Maximum Method Mean: } & 5.5960 \\ \text { Minimum Method SD: } & 0.0503 \\ \text { Maximum Method SD: } & 0.2785 \\ \text { Mean of Method Means: } & 4.6963 \\ \text { SD of Method Means: } & 1.2723 \\ \text { SD of Method Means (wrt to grand mean): } & 1.3115 \\ \text { Within Method (pooled) SD: } & 0.2293 \\ \text { Within Method (pooled) Variance: } & 0.0526 \\ & \\ \text { Method: BOB (Bound on Bias) } & \\ \text { Estimate of Consensus Mean: } & 4.6963 \\ \text { Within Method Uncertainty: } & 0.0640 \\ \text { Between Method Uncertainty: } & 0.5194 \\ \text { Standard Uncertainty }(k=1): & 0.5233 \\ \text { Expanded Uncertainty }(k=2): & 1.0467 \\ \text { Lower 95 \% }(k=2) \text { Confidence Limit: } & 3.6496 \\ \text { Upper 95 \% }(k=2) \text { Confidence Limit: } & 5.7430\end{aligned}$

Results by method

\begin{tabular}{cccccc}
\hline $\begin{array}{c}\text { Method } \\
\text { ID }\end{array}$ & $n(i)$ & Mean & Variance & $\begin{array}{c}\text { Standard } \\
\text { Deviation }\end{array}$ & $\begin{array}{c}\text { Standard } \\
\text { Deviation } \\
\text { of the Mean }\end{array}$ \\
\hline XRD & 3 & 3.7967 & 0.0025 & 0.0503 & 0.0291 \\
SEM & 5 & 5.5960 & 0.0776 & 0.2785 & 0.1246 \\
\hline
\end{tabular}




\section{B.4 Tetracalcium aluminoferrite}

\section{Summary}

\begin{aligned} & Number of Observations: \multicolumn{1}{c}{8} \\ & Grand Mean: 8.7275 \\ & Grand Standard Deviation: 1.6680 \\ & Total Number of Methods: \multicolumn{1}{c}{2} \\ & Minimum Method Mean: 7.5420 \\ & Maximum Method Mean: 10.7033 \\ & Minimum Method SD: 0.1514 \\ & Maximum Method SD: 0.4154 \\ & Mean of Method Means: 9.1227 \\ & SD of Method Means: 2.2354 \\ & SD of Method Means (wrt to grand mean): 2.3042 \\ & Within Method (pooled) SD: 0.3502 \\ & Within Method (pooled) Variance: 0.1227 \\ & Method: BOB (Bound on Bias) \\ & Estimate of Consensus Mean: 9.1227 \\ & Within Method Uncertainty: 0.1027 \\ & Between Method Uncertainty: 0.9126 \\ & Standard Uncertainty ( $k=1): 0.9184 \\ &$ Expanded Uncertainty ( $k=2): 1.8367 \\ &$ Lower 95 \% $k=$ 2) Confidence Limit: 7.2860 \\ & Upper 95 \% ( $k=2$ 2) Confidence Limit: 10.9594 \\ &\end{aligned}

Results by method

\begin{tabular}{cccccc}
\hline $\begin{array}{c}\text { Method } \\
\text { ID }\end{array}$ & $n(i)$ & Mean & Variance & $\begin{array}{c}\text { Standard } \\
\text { Deviation }\end{array}$ & $\begin{array}{c}\text { Standard } \\
\text { Deviation } \\
\text { of the Mean }\end{array}$ \\
\hline XRD & 3 & 10.7033 & 0.0229 & 0.1514 & 0.0874 \\
SEM & 5 & 7.5420 & 0.1725 & 0.4154 & 0.1858 \\
\hline
\end{tabular}




\section{B.5 Periclase}

\section{Summary}

$\begin{aligned} \text { Number of Observations: } & 8 \\ \text { Grand Mean: } & 4.4512 \\ \text { Grand Standard Deviation: } & 1.5528 \\ \text { Total Number of Methods: } & 2 \\ \text { Minimum Method Mean: } & 3.4400 \\ \text { Maximum Method Mean: } & 5.0580 \\ \text { Minimum Method SD: } & 0.0400 \\ \text { Maximum Method SD: } & 1.7297 \\ \text { Mean of Method Means: } & 4.2490 \\ \text { SD of Method Means: } & 1.1441 \\ \text { Within Method (pooled) SD: } & 1.1793 \\ \text { SD of Method Means (wrt to grand mean): } & 1.4125 \\ \text { Within Method (pooled) Variance: } & 1.9951 \\ & \\ \text { Method: BOB (Bound on Bias) } & \\ \text { Estimate of Consensus Mean: } & 4.2490 \\ \text { Within Method Uncertainty: } & 0.3869 \\ \text { Between Method Uncertainty: } & 0.4671 \\ \text { Standard Uncertainty }(k=1): & 0.6065 \\ \text { Expanded Uncertainty }(k=2): & 1.2131 \\ \text { Lower 95 \% }(k=2) \text { Confidence Limit: } & 3.0359 \\ \text { Upper 95 \% }(k=2) \text { Confidence Limit: } & 5.4621\end{aligned}$

\section{Results by method}

\begin{tabular}{cccccc}
\hline $\begin{array}{c}\text { Method } \\
\text { ID }\end{array}$ & $n(i)$ & Mean & Variance & $\begin{array}{c}\text { Standard } \\
\text { Deviation }\end{array}$ & $\begin{array}{c}\text { Standard } \\
\text { Deviation } \\
\text { of the Mean }\end{array}$ \\
\hline XRD & 3 & 3.4400 & 0.0016 & 0.0400 & 0.0231 \\
SEM & 5 & 5.0580 & 2.9918 & 1.7297 & 0.7735 \\
\hline
\end{tabular}




\section{B.6 Alkali sulfates}

\section{Summary}

$\begin{aligned} & \text { Number of Observations: } 8 \\ & \text { Grand Mean: } 0.5625 \\ & \text { Grand Standard Deviation: } 0.4228 \\ & \text { Total Number of Methods: } 2 \\ & \text { Minimum Method Mean: } 0.2000 \\ & \text { Maximum Method Mean: } 0.7800 \\ & \text { Minimum Method SD: } 0.0173 \\ & \text { Maximum Method SD: } 0.3936 \\ & \text { Mean of Method Means: } 0.4900 \\ & \text { SD of Method Means: } 0.4101 \\ & \text { SD of Method Means (wrt to grand mean): } 0.4227 \\ & \text { Within Method (pooled) SD: } 0.3216 \\ & \text { Within Method (pooled) Variance: } 0.1034 \\ & \text { Method: BOB (Bound on Bias) } \\ & \text { Estimate of Consensus Mean: } 0.4900 \\ & \text { Within Method Uncertainty: } 0.0882 \\ & \text { Between Method Uncertainty: } 0.1674 \\ &\text { Standard Uncertainty ( } k=1): 0.1892 \\ & \text { Expanded Uncertainty }(k=2): 0.3784 \\ & \text { Lower 95 \% }(k=\text { 2) Confidence Limit: } 0.1116 \\ & \text { Upper 95 \% }(k=\text { 2) Confidence Limit: } 0.8684 \\ &\end{aligned}$

Results by method

\begin{tabular}{cccccc}
\hline $\begin{array}{c}\text { Method } \\
\text { ID }\end{array}$ & $n(i)$ & Mean & Variance & $\begin{array}{c}\text { Standard } \\
\text { Deviation }\end{array}$ & $\begin{array}{c}\text { Standard } \\
\text { Deviation } \\
\text { of the Mean }\end{array}$ \\
\hline XRD & 3 & 0.2000 & 0.0003 & 0.0173 & 0.0100 \\
SEM & 5 & 0.7800 & 0.1550 & 0.3936 & 0.1760 \\
\hline
\end{tabular}




\section{B.7 Calcite}

\section{Summary}

$\begin{aligned} \text { Number of Observations: } & 8 \\ \text { Grand Mean: } & 2.8463 \\ \text { Grand Standard Deviation: } & 0.7119 \\ \text { Total Number of Methods: } & 2 \\ \text { Minimum Method Mean: } & 2.5860 \\ \text { Maximum Method Mean: } & 3.2800 \\ \text { Minimum Method SD: } & 0.1411 \\ \text { Maximum Method SD: } & 0.8069 \\ \text { Mean of Method Means: } & 2.9330 \\ \text { SD of Method Means: } & 0.4907 \\ \text { WD of Method Means (wrt to grand mean): } & 0.5058 \\ \text { Within Method (pooled) SD: } & 0.6639 \\ \text { Within Method (pooled) Variance: } & 0.4407 \\ & \\ \text { Method: BOB (Bound on Bias) } & \\ \text { Estimate of Consensus Mean: } & 2.9330 \\ \text { Within Method Uncertainty: } & 0.1850 \\ \text { Between Method Uncertainty: } & 0.2003 \\ \text { Standard Uncertainty }(k=1): & 0.2727 \\ \text { Expanded Uncertainty }(k=2): & 0.5453 \\ \text { Lower 95 \% }(k=2) \text { Confidence Limit: } & 2.3877 \\ \text { Upper 95 \% }(k=2) \text { Confidence Limit: } & 3.4783\end{aligned}$

\section{Results by method}

\begin{tabular}{cccccc}
\hline $\begin{array}{c}\text { Method } \\
\text { ID }\end{array}$ & $n(i)$ & Mean & Variance & $\begin{array}{c}\text { Standard } \\
\text { Deviation }\end{array}$ & $\begin{array}{c}\text { Standard } \\
\text { Deviation } \\
\text { of the Mean }\end{array}$ \\
\hline XRD & 3 & 3.2800 & 0.0199 & 0.1411 & 0.0814 \\
SEM & 5 & 2.5860 & 0.6511 & 0.8069 & 0.3609 \\
\hline
\end{tabular}




\section{B.8 Gypsum}

Note: This analysis includes gypsum, bassanite, and anhydrite forms together.

\section{Summary}

$\begin{aligned} \text { Number of Observations: } & 8 \\ \text { Grand Mean: } & 2.7237 \\ \text { Grand Standard Deviation: } & 0.3777 \\ \text { Total Number of Methods: } & 2 \\ \text { Minimum Method Mean: } & 2.4700 \\ \text { Maximum Method Mean: } & 3.1467 \\ \text { Minimum Method SD: } & 0.0462 \\ \text { Maximum Method SD: } & 0.1843 \\ \text { Mean of Method Means: } & 2.8083 \\ \text { SD of Method Means: } & 0.4785 \\ \text { SD of Method Means (wrt to grand mean): } & 0.4932 \\ \text { Within Method (pooled) SD: } & 0.1528 \\ \text { Within Method (pooled) Variance: } & 0.0233 \\ & \\ \text { Method: BOB (Bound on Bias) } & \\ \text { Estimate of Consensus Mean: } & 2.8083 \\ \text { Within Method Uncertainty: } & 0.0433 \\ \text { Between Method Uncertainty: } & 0.1953 \\ \text { Standard Uncertainty }(k=1): & 0.2001 \\ \text { Expanded Uncertainty }(k=2): & 0.4002 \\ \text { Lower 95 \% }(k=2) \text { Confidence Limit: } & 2.4082 \\ \text { Upper 95 \% }(k=2) \text { Confidence Limit: } & 3.2085\end{aligned}$

\section{Results by method}

\begin{tabular}{cccccc}
\hline $\begin{array}{c}\text { Method } \\
\text { ID }\end{array}$ & $n(i)$ & Mean & Variance & $\begin{array}{c}\text { Standard } \\
\text { Deviation }\end{array}$ & $\begin{array}{c}\text { Standard } \\
\text { Deviation } \\
\text { of the Mean }\end{array}$ \\
\hline XRD & 3 & 3.1467 & 0.0021 & 0.0462 & 0.0267 \\
SEM & 5 & 2.4700 & 0.0339 & 0.1843 & 0.0824 \\
\hline
\end{tabular}




\section{B.9 Dolomite}

\section{Summary}

$\begin{aligned} \text { Number of Observations: } & 8 \\ \text { Grand Mean: } & 0.7475 \\ \text { Grand Standard Deviation: } & 0.5882 \\ \text { Total Number of Methods: } & 2 \\ \text { Minimum Method Mean: } & 0.5460 \\ \text { Maximum Method Mean: } & 1.0833 \\ \text { Minimum Method SD: } & 0.0252 \\ \text { Maximum Method SD: } & 0.6855 \\ \text { Mean of Method Means: } & 0.8147 \\ \text { SD of Method Means: } & 0.3800 \\ \text { SD of Method Means (wrt to grand mean): } & 0.3916 \\ \text { Within Method (pooled) SD: } & 0.5599 \\ \text { Within Method (pooled) Variance: } & 0.3135 \\ \text { Method: BOB (Bound on Bias) } & \\ \text { Estimate of Consensus Mean: } & 0.8147 \\ \text { Within Method Uncertainty: } & 0.1534 \\ \text { Between Method Uncertainty: } & 0.1551 \\ \text { Standard Uncertainty ( } k=1): & 0.2182 \\ \text { Expanded Uncertainty ( } k=2): & 0.4364 \\ \text { Lower 95 \% }(k=2) \text { Confidence Limit: } & 0.3783 \\ \text { Upper 95 \% ( } k=2 \text { ) Confidence Limit: } & 1.2510\end{aligned}$

\section{Results by method}

\begin{tabular}{|c|c|c|c|c|c|}
\hline $\begin{array}{l}\text { Method } \\
\text { ID }\end{array}$ & $n(i)$ & Mean & Variance & $\begin{array}{l}\text { Standard } \\
\text { Deviation }\end{array}$ & $\begin{array}{c}\text { Standard } \\
\text { Deviation } \\
\text { of the Mean }\end{array}$ \\
\hline XRD & 3 & 1.0833 & 0.0006 & 0.0252 & 0.0145 \\
\hline SEM & 5 & 0.5460 & 0.4699 & 0.6855 & 0.3066 \\
\hline
\end{tabular}




\section{B.10 Quartz}

\section{Summary}

$\begin{aligned} \text { Number of Observations: } & 8 \\ \text { Grand Mean: } & 0.6250 \\ \text { Grand Standard Deviation: } & 0.6160 \\ \text { Total Number of Methods: } & 2 \\ \text { Minimum Method Mean: } & 0.2000 \\ \text { Maximum Method Mean: } & 0.8800 \\ \text { Minimum Method SD: } & 0.0265 \\ \text { Maximum Method SD: } & 0.6686 \\ \text { Mean of Method Means: } & 0.5400 \\ \text { SD of Method Means: } & 0.4808 \\ \text { Within Method (pooled) SD: } & 0.4956 \\ \text { SD of Method Means (wrt to grand mean): } & 0.5461 \\ \text { Within Method (pooled) Variance: } & 0.2982 \\ \text { Method: BOB (Bound on Bias) } & \\ \text { Estimate of Consensus Mean: } & 0.5400 \\ \text { Within Method Uncertainty: } & 0.1497 \\ \text { Between Method Uncertainty: } & 0.1963 \\ \text { Standard Uncertainty }(k=1): & 0.2469 \\ \text { Expanded Uncertainty }(k=2): & 0.4937 \\ \text { Lower 95 \% }(k=2) \text { Confidence Limit: } & 0.0463 \\ \text { Upper 95 \% }(k=2) \text { Confidence Limit: } & 1.0337\end{aligned}$

\section{Results by method}

\begin{tabular}{cccccc}
\hline $\begin{array}{c}\text { Method } \\
\text { ID }\end{array}$ & $n(i)$ & Mean & Variance & $\begin{array}{c}\text { Standard } \\
\text { Deviation }\end{array}$ & $\begin{array}{c}\text { Standard } \\
\text { Deviation } \\
\text { of the Mean }\end{array}$ \\
\hline XRD & 3 & 0.2000 & 0.0007 & 0.0265 & 0.0153 \\
SEM & 5 & 0.8800 & 0.4470 & 0.6686 & 0.2990 \\
\hline
\end{tabular}




\section{Appendix C. Consensus Phase Mass Percentage Values for Cement 3-74}

\section{C.1 Alite}

Summary

\begin{tabular}{rr} 
Number of Observations: & \multicolumn{1}{c}{9} \\
Grand Mean: & 58.2322 \\
Grand Standard Deviation: & 2.0933 \\
Total Number of Labs: & \multicolumn{1}{c}{2} \\
Minimum Lab Mean: & 57.8783 \\
Maximum Lab Mean: & 58.9400 \\
Minimum Lab SD: & 0.6963 \\
Maximum Lab SD: & 2.5232 \\
Mean of Lab Means: & 58.4092 \\
SD of Lab Means: & 0.7507 \\
SD of Lab Means (wrt to grand mean): & 0.7913 \\
Within Lab (pooled) SD: & 2.1647 \\
Within Lab (pooled) Variance: & 4.6860 \\
& \\
Method: BOB (Bound on Bias) & \\
Estimate of Consensus Mean: & 58.4092 \\
Within Lab Uncertainty: & 0.5529 \\
Between Lab Uncertainty: & 0.3065 \\
Standard Uncertainty ( $k=1):$ & 0.6321 \\
Expanded Uncertainty $(k=2):$ & 1.2643 \\
Lower 95 \% ( $k=2$ 2) Confidence Limit: & 57.1449 \\
Upper 95 \% ( $k=$ 2) Confidence Limit: & 59.6735
\end{tabular}

Results by method

\begin{tabular}{|c|c|c|c|c|c|}
\hline $\begin{array}{l}\text { Method } \\
\text { ID }\end{array}$ & $n(i)$ & Mean & Variance & $\begin{array}{c}\text { Standard } \\
\text { Deviation }\end{array}$ & $\begin{array}{c}\text { Standard } \\
\text { Deviation } \\
\text { of the Mean }\end{array}$ \\
\hline XRD & 3 & 58.9400 & 0.4849 & 0.6963 & 0.4020 \\
\hline SEM & 6 & 57.8783 & 6.3665 & 2.5232 & 1.0301 \\
\hline
\end{tabular}




\section{C.2 Belite}

\section{Summary}

\begin{tabular}{rr} 
Number of Observations: & \multicolumn{1}{c}{9} \\
Grand Mean: & 11.7378 \\
Grand Standard Deviation: & 1.8572 \\
Total Number of Labs: & \multicolumn{1}{c}{2} \\
Minimum Lab Mean: & 10.7967 \\
Maximum Lab Mean: & 12.2083 \\
Minimum Lab SD: & 0.7893 \\
Maximum Lab SD: & 2.1148 \\
Mean of Lab Means: & 11.5025 \\
SD of Lab Means: & 0.9982 \\
WD of Lab Means (wrt to grand mean): & 1.0522 \\
Within Lab (pooled) SD: & 1.8365 \\
Within Lab (pooled) Variance: & 3.3726 \\
& \\
& \\
Method: BOB (Bound on Bias) & \\
Estimate of Consensus Mean: & 11.5025 \\
Within Lab Uncertainty: & 0.4881 \\
Between Lab Uncertainty: & 0.4075 \\
Standard Uncertainty $(k=1):$ & 0.6359 \\
Expanded Uncertainty $(k=2):$ & 1.2717 \\
Lower 95 \% $(k=2)$ Confidence Limit: & 10.2308 \\
Upper 95 \% $(k=2)$ Confidence Limit: & 12.7742
\end{tabular}

\section{Results by method}

\begin{tabular}{cccccc}
\hline $\begin{array}{c}\text { Method } \\
\text { ID }\end{array}$ & $n(i)$ & Mean & Variance & $\begin{array}{c}\text { Standard } \\
\text { Deviation }\end{array}$ & $\begin{array}{c}\text { Standard } \\
\text { Deviation } \\
\text { of the Mean }\end{array}$ \\
\hline 1 & 3 & 10.7967 & 0.6230 & 0.7893 & 0.4557 \\
& 6 & 12.2083 & 4.4724 & 2.1148 & 0.8634 \\
\hline
\end{tabular}




\section{C.3 Tricalcium aluminate}

\section{Summary}

$\begin{aligned} \text { Number of Observations: } & 9 \\ \text { Grand Mean: } & 9.0789 \\ \text { Grand Standard Deviation: } & 1.3975 \\ \text { Total Number of Labs: } & 2 \\ \text { Minimum Lab Mean: } & 9.0217 \\ \text { Maximum Lab Mean: } & 9.1933 \\ \text { Minimum Lab SD: } & 0.0451 \\ \text { Maximum Lab SD: } & 1.7641 \\ \text { Mean of Lab Means: } & 9.1075 \\ \text { SD of Lab Means: } & 0.1214 \\ \text { Within Lab (pooled) SD: } & 0.1280 \\ \text { SD of Lab Means (wrt to grand mean): } & 1.4912 \\ \text { Within Lab (pooled) Variance: } & 2.2235 \\ & \\ \text { Method: BOB (Bound on Bias) } & \\ \text { Estimate of Consensus Mean: } & 9.1075 \\ \text { Within Lab Uncertainty: } & 0.3603 \\ \text { Between Lab Uncertainty: } & 0.0496 \\ \text { Standard Uncertainty }(k=1): & 0.3637 \\ \text { Expanded Uncertainty }(k=2): & 0.7275 \\ \text { Lower 95 \% }(k=2) \text { Confidence Limit: } & 8.3800 \\ \text { Upper 95 \% }(k=\text { 2) Confidence Limit: } & 9.8350\end{aligned}$

Results by method

\begin{tabular}{cccccc}
\hline $\begin{array}{c}\text { Method } \\
\text { ID }\end{array}$ & $n(i)$ & Mean & Variance & $\begin{array}{c}\text { Standard } \\
\text { Deviation }\end{array}$ & $\begin{array}{c}\text { Standard } \\
\text { Deviation } \\
\text { of the Mean }\end{array}$ \\
\hline XRD & 3 & 9.1933 & 0.0020 & 0.0451 & 0.0260 \\
SEM & 6 & 9.0217 & 3.1121 & 1.7641 & 0.7202 \\
\hline
\end{tabular}




\section{C.4 Tetracalcium aluminoferrite}

\section{Summary}

$\begin{aligned} \text { Number of Observations: } & 9 \\ \text { Grand Mean: } & 9.1078 \\ \text { Grand Standard Deviation: } & 1.1585 \\ \text { Total Number of Labs: } & 2 \\ \text { Minimum Lab Mean: } & 9.0717 \\ \text { Maximum Lab Mean: } & 9.1800 \\ \text { Minimum Lab SD: } & 0.0866 \\ \text { Maximum Lab SD: } & 1.4628 \\ \text { Mean of Lab Means: } & 9.1258 \\ \text { SD of Lab Means: } & 0.0766 \\ \text { SD of Lab Means (wrt to grand mean): } & 0.0807 \\ \text { Within Lab (pooled) SD: } & 1.2372 \\ \text { Within Lab (pooled) Variance: } & 1.5306 \\ \text { Method: BOB (Bound on Bias) } & \\ \text { Estimate of Consensus Mean: } & 9.1258 \\ \text { Within Lab Uncertainty: } & 0.2996 \\ \text { Between Lab Uncertainty: } & 0.0313 \\ \text { Standard Uncertainty ( } k=1): & 0.3013 \\ \text { Expanded Uncertainty }(k=2): & 0.6025 \\ \text { Lower 95\% } k=2) \text { Confidence Limit: } & 8.5233 \\ \text { Upper 95\% } k=2 \text { 2) Confidence Limit: } & 9.7284\end{aligned}$

\section{Results by method}

\begin{tabular}{|c|c|c|c|c|c|}
\hline $\begin{array}{l}\text { Method } \\
\text { ID }\end{array}$ & $n(i)$ & Mean & Variance & $\begin{array}{l}\text { Standard } \\
\text { Deviation }\end{array}$ & $\begin{array}{c}\text { Standard } \\
\text { Deviation } \\
\text { of the Mean }\end{array}$ \\
\hline XRD & 3 & 9.1800 & 0.0075 & 0.0866 & 0.0500 \\
\hline SEM & 6 & 9.0717 & 2.1398 & 1.4628 & 0.5972 \\
\hline
\end{tabular}




\section{C.5 Periclase}

\section{Summary}

$\begin{aligned} \text { Number of Observations: } & 9 \\ \text { Grand Mean: } & 1.5489 \\ \text { Grand Standard Deviation: } & 0.3573 \\ \text { Total Number of Labs: } & 2 \\ \text { Minimum Lab Mean: } & 1.5400 \\ \text { Maximum Lab Mean: } & 1.5667 \\ \text { Minimum Lab SD: } & 0.0058 \\ \text { Maximum Lab SD: } & 0.4516 \\ \text { Mean of Lab Means: } & 1.5533 \\ \text { SD of Lab Means: } & 0.0189 \\ \text { SD of Lab Means (wrt to grand mean): } & 0.0199 \\ \text { Within Lab (pooled) SD: } & 0.3817 \\ \text { Within Lab (pooled) Variance: } & 0.1457 \\ \text { Method: BOB (Bound on Bias) } & \\ \text { Estimate of Consensus Mean: } & 1.5533 \\ \text { Within Lab Uncertainty: } & 0.0922 \\ \text { Between Lab Uncertainty: } & 0.0077 \\ \text { Standard Uncertainty }(k=1): & 0.0925 \\ \text { Expanded Uncertainty }(k=2): & 0.1850 \\ \text { Lower 95 \% } k=2) \text { Confidence Limit: } & 1.3683 \\ \text { Upper 95 \% } k=2) \text { Confidence Limit: } & 1.7384\end{aligned}$

\section{Results by method}

\begin{tabular}{cccccc}
$\begin{array}{c}\text { Method } \\
\text { ID }\end{array}$ & $n(i)$ & Mean & Variance & $\begin{array}{c}\text { Standard } \\
\text { Deviation }\end{array}$ & $\begin{array}{c}\text { Standard } \\
\text { Deviation } \\
\text { of the Mean }\end{array}$ \\
\hline XRD & 3 & 1.5667 & 0.0000 & 0.0058 & 0.0033 \\
SEM & 6 & 1.5400 & 0.2039 & 0.4516 & 0.1844 \\
\hline
\end{tabular}




\section{C.6 Alkali sulfates}

\section{Summary}

$\begin{aligned} \text { Number of Observations: } & 9 \\ \text { Grand Mean: } & 1.7344 \\ \text { Grand Standard Deviation: } & 0.2466 \\ \text { Total Number of Labs: } & 2 \\ \text { Minimum Lab Mean: } & 1.6767 \\ \text { Maximum Lab Mean: } & 1.8500 \\ \text { Minimum Lab SD: } & 0.0173 \\ \text { Maximum Lab SD: } & 0.2919 \\ \text { Mean of Lab Means: } & 1.7633 \\ \text { SD of Lab Means: } & 0.1226 \\ \text { SD of Lab Means (wrt to grand mean): } & 0.1292 \\ \text { Within Lab (pooled) SD: } & 0.2468 \\ \text { Within Lab (pooled) Variance: } & 0.0609 \\ \text { Method: BOB (Bound on Bias) } & \\ \text { Estimate of Consensus Mean: } & 1.7633 \\ \text { Within Lab Uncertainty: } & 0.0598 \\ \text { Between Lab Uncertainty: } & 0.0500 \\ \text { Standard Uncertainty ( } k=1): & 0.0780 \\ \text { Expanded Uncertainty }(k=2): & 0.1559 \\ \text { Lower 95 \% ( } k=2) \text { Confidence Limit: } & 1.6074 \\ \text { Upper 95 \% ( } k=2 \text { 2) Confidence Limit: } & 1.9193\end{aligned}$

\section{Results by method}

\begin{tabular}{|c|c|c|c|c|c|}
\hline $\begin{array}{l}\text { Method } \\
\text { ID }\end{array}$ & $n(i)$ & Mean & Variance & $\begin{array}{l}\text { Standard } \\
\text { Deviation }\end{array}$ & $\begin{array}{c}\text { Standard } \\
\text { Deviation } \\
\text { of the Mean }\end{array}$ \\
\hline XRD & 3 & 1.8500 & 0.0003 & 0.0173 & 0.0100 \\
\hline SEM & 6 & 1.6767 & 0.0852 & 0.2919 & 0.1192 \\
\hline
\end{tabular}




\section{C.7 Calcite}

\section{Summary}

$\begin{aligned} \text { Number of Observations: } & 9 \\ \text { Grand Mean: } & 1.3189 \\ \text { Grand Standard Deviation: } & 0.3846 \\ \text { Total Number of Labs: } & 2 \\ \text { Minimum Lab Mean: } & 1.2833 \\ \text { Maximum Lab Mean: } & 1.3900 \\ \text { Minimum Lab SD: } & 0.1000 \\ \text { Maximum Lab SD: } & 0.4776 \\ \text { Mean of Lab Means: } & 1.3367 \\ \text { SD of Lab Means: } & 0.0754 \\ \text { WD of Lab Means (wrt to grand mean): } & 0.0795 \\ \text { Within Lab (pooled) SD: } & 0.4071 \\ \text { Within Lab (pooled) Variance: } & 0.1658 \\ & \\ \text { Method: BOB (Bound on Bias) } & \\ \text { Estimate of Consensus Mean: } & 1.3367 \\ \text { Within Lab Uncertainty: } & 0.1017 \\ \text { Between Lab Uncertainty: } & 0.0308 \\ \text { Standard Uncertainty }(k=1): & 0.1062 \\ \text { Expanded Uncertainty }(k=2): & 0.2125 \\ \text { Lower 95 \% }(k=2) \text { Confidence Limit: } & 1.1242 \\ \text { Upper 95 \% ( } k=2 \text { ) Confidence Limit: } & 1.5491\end{aligned}$

\section{Results by method}

\begin{tabular}{cccccc}
\hline $\begin{array}{c}\text { Method } \\
\text { ID }\end{array}$ & $n(i)$ & Mean & Variance & $\begin{array}{c}\text { Standard } \\
\text { Deviation }\end{array}$ & $\begin{array}{c}\text { Standard } \\
\text { Deviation } \\
\text { of the Mean }\end{array}$ \\
\hline XRD & 3 & 1.3900 & 0.0100 & 0.1000 & 0.0577 \\
SEM & 6 & 1.2833 & 0.2281 & 0.4776 & 0.1950 \\
\hline
\end{tabular}




\section{C.8 Gypsum}

Note: This analysis includes gypsum, bassanite, and anhydrite forms together.

\section{Summary}

$\begin{aligned} \text { Number of Observations: } & 9 \\ \text { Grand Mean: } & 3.8378 \\ \text { Grand Standard Deviation: } & 0.5000 \\ \text { Total Number of Labs: } & 2 \\ \text { Minimum Lab Mean: } & 3.5583 \\ \text { Maximum Lab Mean: } & 4.3967 \\ \text { Minimum Lab SD: } & 0.0666 \\ \text { Maximum Lab SD: } & 0.3422 \\ \text { Mean of Lab Means: } & 3.9775 \\ \text { SD of Lab Means: } & 0.5928 \\ \text { SD of Lab Means (wrt to grand mean): } & 0.6249 \\ \text { Within Lab (pooled) SD: } & 0.2914 \\ \text { Within Lab (pooled) Variance: } & 0.0849 \\ & \\ \text { Method: BOB (Bound on Bias) } & \\ \text { Estimate of Consensus Mean: } & 3.9775 \\ \text { Within Lab Uncertainty: } & 0.0724 \\ \text { Between Lab Uncertainty: } & 0.2420 \\ \text { Standard Uncertainty }(k=1): & 0.2526 \\ \text { Expanded Uncertainty }(k=2): & 0.5052 \\ \text { Lower 95 \% }(k=2) \text { Confidence Limit: } & 3.4723 \\ \text { Upper 95 \% }(k=2) \text { Confidence Limit: } & 4.4827\end{aligned}$

\section{Results by method}

\begin{tabular}{cccccc}
\hline $\begin{array}{c}\text { Method } \\
\text { ID }\end{array}$ & $n(i)$ & Mean & Variance & $\begin{array}{c}\text { Standard } \\
\text { Deviation }\end{array}$ & $\begin{array}{c}\text { Standard } \\
\text { Deviation } \\
\text { of the Mean }\end{array}$ \\
\hline XRD & 3 & 4.3967 & 0.0044 & 0.0666 & 0.0384 \\
SEM & 6 & 3.5583 & 0.1171 & 0.3422 & 0.1397 \\
\hline
\end{tabular}




\section{C.9 Dolomite}

Summary

$\begin{aligned} \text { Number of Observations: } & 9 \\ \text { Grand Mean: } & 1.8867 \\ \text { Grand Standard Deviation: } & 0.9424 \\ \text { Total Number of Labs: } & 2 \\ \text { Minimum Lab Mean: } & 1.8733 \\ \text { Maximum Lab Mean: } & 1.9133 \\ \text { Minimum Lab SD: } & 0.1607 \\ \text { Maximum Lab SD: } & 1.1874 \\ \text { Mean of Lab Means: } & 1.8933 \\ \text { SD of Lab Means: } & 0.0283 \\ \text { SD of Lab Means (wrt to grand mean): } & 0.0298 \\ \text { Within Lab (pooled) SD: } & 1.0072 \\ \text { Within Lab (pooled) Variance: } & 1.0145 \\ & \\ \text { Method: BOB (Bound on Bias) } & \\ \text { Estimate of Consensus Mean: } & 1.8933 \\ \text { Within Lab Uncertainty: } & 0.2468 \\ \text { Between Lab Uncertainty: } & 0.0115 \\ \text { Standard Uncertainty }(k=1): & 0.2470 \\ \text { Expanded Uncertainty }(k=2): & 0.4941 \\ \text { \%ower 95 }(k=2) \text { Confidence Limit: } & 1.3992 \\ \text { Upper 95 \% } k=2) \text { Confidence Limit: } & 2.3874\end{aligned}$

Results by method

\begin{tabular}{|c|c|c|c|c|c|}
\hline $\begin{array}{l}\text { Method } \\
\text { ID }\end{array}$ & $n(i)$ & Mean & Variance & $\begin{array}{l}\text { Standard } \\
\text { Deviation }\end{array}$ & $\begin{array}{c}\text { Standard } \\
\text { Deviation } \\
\text { of the Mean }\end{array}$ \\
\hline XRD & 3 & 1.9133 & 0.0258 & 0.1607 & 0.0928 \\
\hline SEM & 6 & 1.8733 & 1.4099 & 1.1874 & 0.4848 \\
\hline
\end{tabular}




\section{C.10 Quartz}

\section{Summary}

$\begin{aligned} \text { Number of Observations: } & 9 \\ \text { Grand Mean: } & 0.4167 \\ \text { Grand Standard Deviation: } & 0.2263 \\ \text { Total Number of Labs: } & 2 \\ \text { Minimum Lab Mean: } & 0.4000 \\ \text { Maximum Lab Mean: } & 0.4500 \\ \text { Minimum Lab SD: } & 0.1908 \\ \text { Maximum Lab SD: } & 0.2577 \\ \text { Mean of Lab Means: } & 0.4250 \\ \text { SD of Lab Means: } & 0.0354 \\ \text { SD of Lab Means (wrt to grand mean): } & 0.0373 \\ \text { Within Lab (pooled) SD: } & 0.2405 \\ \text { Within Lab (pooled) Variance: } & 0.0578\end{aligned}$

\section{Results by method}

\begin{tabular}{|c|c|c|c|c|c|}
\hline $\begin{array}{c}\text { Method } \\
\text { ID }\end{array}$ & $n(i)$ & Mean & Variance & $\begin{array}{l}\text { Standard } \\
\text { Deviation }\end{array}$ & $\begin{array}{c}\text { Standard } \\
\text { Deviation } \\
\text { of the Mean }\end{array}$ \\
\hline XRD & 3 & 0.4500 & 0.0364 & 0.1908 & 0.1102 \\
\hline SEM & 6 & 0.4000 & 0.0664 & 0.2577 & 0.1052 \\
\hline
\end{tabular}

\section{Acknowledgments}

Max Peltz is gratefully acknowledged for providing measurements of particle size distribution for the cements. Dale Bentz and Ed Garboczi are thanked for thoroughly reviewing the manuscript.

\section{References}

[1] L. T. Brownmiller and R. H. Bogue. "The X-Ray Method Applied to a Study of the Constitution of Portland Cement”. Bureau of Standards J. Res. 5 (1930), pp. 813-830. http://dx.doi.org/10.6028/jres.005.051

[2] H. Le Châtelier. "Recherches Expérimentales sur la Constitution des Ciments et la Théorie de Leur Prise”. Paris Acad. Sci. Compt. Rend. 94 (1882), pp. 867-869.

[3] H. Le Châtelier. Experimental Researches on the Constitution of Hydraulic Mortars (English Translation). New York: McGraw-Hill, 1905.

[4] A. E. Törnebohm. “Die Petrographie des Portland-Cements”. Thonind.-Ztg. 21.110 (1897), pp. 1148-1151.

[5] ASTM C 1365: Standard Test Method for Determination of the Proportion of Phases in Portland Cement and Portland-Cement Clinker Using X-ray Diffraction Analysis”. Annual Book of ASTM Standards. Vol. 4.01. West Conshohocken, PA: ASTM International, 2014.

[6] J. E. Post and D. L. Bish. "Rietveld Refinement of Crystal Structures Using Powder X-Ray Diffraction Data”. Reviews in Mineralogy and Geochemistry 20 (1989), pp. 277-308.

[7] M. A. Delesse. "Procédé Mecanique pour Determiner la Composition des Roches (Mechanical Methods for Determining the Composition of Rocks)". Annales des Mines 13 (4th series) (1866), pp. 379-388.

[8] NIST Standard Reference Material 2686a-Portland Cement Clinker. [Online; accessed 21-April-2015]. url: https://wwws.nist.gov/srmors/view_detail.cfm?srm= 2686a. 
[9] P. E. Stutzman, P. Feng, and J. W. Bullard. Quantitative Microstructure Imaging. NIST Technical Note 1877. Washington, D.C.: U.S. Department of Commerce, Apr. 2015.

[10] J. E. Post and D. L. Bish, eds. Reviews in Mineralogy and Geochemistry 20 (1989): Modern Powder Diffraction.

[11] Hal F. W. Taylor. Cement Chemistry. 2nd ed. London: Thomas Telford, 1997.

[12] Miguel A. G. Aranda, Ángeles G. De la Torre, and Laura León-Reina. "Rietveld Quantitative Phase Analysis of OPC Clinkers, Cements and Hydration Products”. Reviews in Mineralogy and Geochemistry 74 (2012), pp. 169-209. http://dx.doi.org/10.2138/rmg.2012.74.5

[13] W. N. Schreiner et al. "Systematic and Random Powder Diffractometer Errors Relevant to Phase Identification". Norelco Reporter 29.1 (Apr. 1982), pp. 42-52.

[14] D. L. Bish and R. C. Reynolds. "Rietveld Refinement of Crystal Structures Using Powder X-Ray Diffraction Data”. Reviews in Mineralogy and Geochemistry 20 (1989), pp. 73-99.

[15] P. S. Whitfield and L. D. Mitchell. "The Effects of Particle Statistics on Rietveld Analysis of Cement”. Z. Kristallogr. Suppl. 30 (2009), pp. 53-59.

[16] W. A. Klemm and J. Skalny. Selective Dissolution of Clinker Minerals and its Applications. Martin Marietta Corporation Technical Report 77-32. 1977, pp. 1-32.

[17] W. A. Gutteridge. "On the Dissolution of the Interstitial Phases in Portland Cement”. Cem. Concr. Res. 9 (1979), pp. 319-324.

[18] B. D. Cullity. Elements of X-Ray Diffraction. New York: Addison-Wesley, 1956.

[19] R. L. Snyder and D. L. Bish. "Quantitative Analysis”. Reviews in Mineralogy and Geochemistry 20 (1989), pp. 101-144.

[20] P. E. Stutzman, J. W. Bullard, and P. Feng. Quantitative Imaging of Clinker and Cement Microstructure. NIST Technical Note 1877. Washington, D.C.: U.S. Department of Commerce, 2015.

[21] P. E. Stutzman, G. Lespinasse, and S. Leigh. Compositional Analysis and Certification of NIST Reference Material Clinker 2686a. NIST Technical Note 1602. Washington, D.C.: U.S. Department of Commerce, 2008.

[22] P. E. Stutzman. "Microscopy of Clinker and Hydraulic Cements”. Rev. Mineralogy Geochem. 74.1 (2012), pp. 101-146.

[23] P. E. Stutzman and J. R. Clifton. "Specimen Preparation for Scanning Electron Microscopy”. Proceedings of the 21st International Conference on Cement Microscopy. Ed. by L. Jany and A. Nisperos. Las Vegas, NV: International Cement Microscopy Association, Apr. 1999, pp. 10-22.

[24] “ASTM C 183: Standard Practice for Sampling and the Amount of Testing of Hydraulic Cement”. Annual Book of ASTM Standards. Vol. 4.01. West Conshohocken, PA: ASTM International, 2014.

[25] B. A. Schumacher et al. "Comparison of Three Methods for Soil Homogenization”. Soil Sci. Am. J. 54.4 (1990), pp. 11871190.

[26] J. I. Goldstein et al. Scanning Electron Microscopy and X-Ray Microanalysis. 2nd. New York: Plenum Press, 1981.

[27] P. E. Stutzman. "Scanning Electron Microscopy Imaging of Hydraulic Cement Microstructure”. Cem. Concr. Composites 26.8 (2004), pp. 957-966.

[28] J. W. Bullard and P. E. Stutzman. "Analysis of CCRL Portland Cement Proficiency Samples Number 151 and Number 152 Using the Virtual Cement and Concrete Testing Laboratory”. Cem. Concr. Res. 36 (2006), pp. 1548-1555.

[29] J. W. Bullard. VCCTL Software. [Online; accessed 16-March-2015]. 2012. url: http://www.nist.gov/el/building_materials/evcctl.cfm.

[30] J. W. Bullard et al. "Coupling Thermodynamics and Digital Image Models to Simulate Hydration and Microstructure Development of Portland Cement Pastes”. J. Mater. Res. 26 (2011), pp. 609-622. http://dx.doi.org/10.1557/jmr.2010.41

[31] J. W. Bullard. MicroChar: An Application for Quantitative Analysis of Cement and Clinker Microstructural Images. NIST Technical Note 1876. Washington, D.C.: U.S. Department of Commerce, Apr. 2015.

[32] H. F. W. Taylor. Cement Chemistry. 2nd ed. London: Thomas Telfor, Ltd., 1997.

[33] J. J. Filliben and A. Heckert. Dataplot Manual. [Online; accessed 20-November-2015]. 2013. url: http://www.itl.nist.gov/div898/software/dataplot/.

[34] J. J. Filliben and A. Heckert. Consensus Mean: Dataplot Manual. [Online; accessed 20-November-2015]. 2013. url: \%5Curl\%7Bhttp://www.itl.nist.gov/div898/software/dataplot/refman1/auxillar/consmean.htm\%7D.

[35] "Guide to the Expression of Uncertainty in Measurement”. ISO/IEC Guide 98:1993. 1st ed. Geneva, Switzerland: ISO, 1993.

[36] B. N. Taylor and C. E. Kuyatt. Guidelines for Evaluating and Expressing the Uncertainty of NIST Measurement Results. NIST Technical Note 1297. [Accessed 3-December-2015]. Washington, D.C.: U.S. Department of Commerce, Apr. 2015. url: http://www.nist.gov/pml/pubs/index.cfm.

[37] M. S. Levenson et al. "An Approach to Combining Results from Multiple Methods Motivated by the ISO GUM". J. Res. Natl. Inst. Stand. Technol. 105.4 (2000), p. 571. http:// dx.doi.org/10.6028/jres.105.047

About the authors: Paul Stutzman is a Physical Scientist in the Inorganic Materials group of the Materials and Structural Systems Division of the Engineering Laboratory at NIST. His interests include measurement of microstructural features of clinker, cement, and mineral admixtures and developing means to assess the interactions of cement - admixtures on the hydration process through real-time quantitative $x$-ray powder diffraction and scanning electron microscopy.

Pan Feng is a PhD candidate in Material Science and Engineering at Southeast University in Nanjing, China, and is currently working at NIST as a guest researcher in the Inorganic Materials group of the Materials and Structural Systems Division of the Engineering Laboratory at NIST. Her research interests 
include computational materials modeling of the chemical degradation of cement-based composites, and characterization of the composition, structure, and reactivity of cementitious minerals.

Jeff Bullard is a Materials Research Engineer in the Inorganic Materials group of the Materials and Structural Systems Division of the Engineering Laboratory at NIST. His research interests include measuring and modeling microstructure and its evolution during hydration or chemical degradation of cement-based materials.

The National Institute of Standards and Technology is an agency of the U.S. Department of Commerce. 